\title{
CARACTERIZAÇÃO DA MORFOLOGIA SUBMARINA DA CADEIA VITÓRIA-TRINDADE E ÁREAS ADJACENTES-ES, COM BASE NA BATIMETRIA PREDITA DO TOPO VERSÃO 14.1
}

\section{SUBMARINE MORPHOLOGY CHARACTERIZATION OF THE VITÓRIA-TRINDADE CHAIN AND THE ADJACENT AREAS, STATE OF ESPÍRITO SANTO, BRAZIL, BASED ON THE PREDICTED BATHYMETRY OF THE TOPO VERSION 14.1}

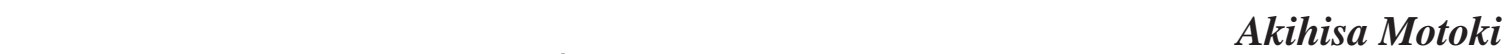 \\ Departamento de Mineralogia e Petrologia Ígnea - Universidade do Estado do Rio de Janeiro (DMPI/UERJ) - Rua São \\ Francisco Xavier 524, Sala A-4023 - Maracanã - Rio de Janeiro/RJ - CEP 20550-900 - \\ e-mail: rochasornamentais@yahoo.com.br \\ Kenji Freire Motoki \\ Departamento de Geologia, Universidade Federal Fluminense (LAGEMAR/UFF) - Avenida General Milton Tavares de \\ Souza, sem número, $4^{\circ}$ andar - Gragoatá - Niterói/RJ - CEP 24210-340-e-mail: kenji_dl@hotmail.com \\ Dean Pereira de Melo \\ Centro de Pesquisa e Desenvolvimento Leopoldo Américo Miguêz de Mello (CENPES/PETROBRAS) - Avenida Horácio \\ Macedo 950, Cidade Universitária - Rio de Janeiro/RJ - CEP 2.941-915 - e-mail: deanmelo@petrobras.com.br
}

Informações sobre o Artigo

Data de Recebimento:

$15 / 09 / 2011$

Data de Aprovação:

$03 / 05 / 2012$

Palavras-chave:

Cadeia Vitória-Trindade; vulcão submarino; batimetria predita

\section{Keywords:}

Vitória-Trindade Chain; submarine volcano; predicted bathymetry

\begin{abstract}
Resumo
Este trabalho apresenta análises geomorfológicas da Cadeia Vitória-Trindade, ES, e das áreas adjacentes por meio de batimetria predita com base no banco de dados do TOPO versão 14.1, que foi disponibilizado em 2011. A referida cadeia de montes submarinos tem comprimento aproximado de $950 \mathrm{~km}$ e direção geral leste-oeste ao longo da latitude $\mathrm{S} 20^{\circ} 30^{\prime}$. É constituída aproximadamente por 30 montes submarinos de forma cônica, que são reconhecidos morfologicamente como edifícios vulcânicos. Os vulcões com altura relativa maior do que $2500 \mathrm{~m}$ têm configuração geográfica altamente linear com a inflexão na parte central. O trecho oriental tem direção $\mathrm{N} 85^{\circ} \mathrm{E}$ e o trecho ocidental, $\mathrm{N} 77^{\circ} \mathrm{W}$. Os montes submarinos são caracterizados morfologicamente por elevação no sopé, edifício vulcânico principal e topo planar. A elevação no sopé tem altura aproximada de $1000 \mathrm{~m}$, os edifícios vulcânicos principais possuem altura variando de $3000 \mathrm{~m}$ a $5000 \mathrm{~m}$ e, o topo planar é em torno de $10 \mathrm{~km}$ de diâmetro e o diâmetro da base é cerca de $30 \mathrm{~km}$. De leste para oeste, a frequência dos montes submarinos aumenta e a elevação no sopé torna-se mais expressiva, indicando que o magmatismo e tectonismo associados aumentam na sua intensidade ao oeste. Na mesma direção, as morfologias de deslizamento ficam maiores e mais frequentes, sugerindo que os vulcões tornam-se mais antigos nesta direção. Os topos planares dos montes submarinos têm profundidade constante em torno de $50 \mathrm{~m}$. A subsidência do assoalho oceânico, que é comum em cadeias de hot-spot, não é observada. Os três bancos do extremo oeste da Cadeia são morfologicamente diferentes dos montes
\end{abstract}


submarinos vulcânicos por terem o topo planar muito extenso, forma não cônica e o ângulo do talude bi-modal. Esses são considerados geomorfologicamente como sendo fragmentos desintegrados da plataforma continental.

\begin{abstract}
This article presents geomorphological analyses of the Vitória-Trindade Chain, State of Espírito Santo, Brazil, and its adjacent areas by means of predicted bathymetry based on the TOPO dataset version 14.1 released in 2011. This seamount chain is about $950 \mathrm{~km}$ long and of east-west general trend, along the latitude S20 30’. It is constituted by more than 30 conical seamounts, which are recognised morphologically to be volcanic edifices. The volcanoes with relative height superior to $2500 \mathrm{~m}$ are of highly linear geographic layout with an inflection at the central part. The eastern half is $\mathrm{N} 85^{\circ} \mathrm{W}$ in direction and the western half, $\mathrm{N} 77^{\circ} \mathrm{W}$. The seamounts are characterised morphologically by foothill elevation, main volcanic edifice, and flat-top. The foothill elevation is about $1000 \mathrm{~m}$ high, the main volcanic edifices are from $3000 \mathrm{~m}$ to $5000 \mathrm{~m}$ in relative height, the flat-tops are about $10 \mathrm{~km}$ in diameter, and the volcano base is approximately $30 \mathrm{~km}$ in diameter. From east to west, the seamounts become more frequent and the foothill elevation becomes more expressive, indicating that the magmatism and associated tectonism become more intense to the west. In the same direction, the landslide morphologies on the volcano flank become larger and more frequent, suggesting that the volcanoes become older to this sense. The flat-top of the seamounts is constantly about $50 \mathrm{~m}$ deep, and ocean bottom subsidence, which is common in hot-spot track, is not observed. The three banks close to the continental are widely different from the volcanic seamounts because of very extensive flat-top, not conical form, and bimodal slope angle. They are considered to be disintegrated pieces of the continental shelf.
\end{abstract}

\section{Introdução}

A Cadeia Vitória-Trindade (Vitória-Trindade Chain) é uma sequência linear de montes submarinos que se situa na região pelágica do Estado do Espírito Santo no Oceano Atlântico Sul. A referida cadeia tem direção geral leste-oeste, ao longo da latitude $20^{\circ} 30^{\prime} \mathrm{S}$, com cerca de $950 \mathrm{~km}$ de comprimento. Ocorrem aproximadamente 30 montes submarinos de forma cônica, que são consideradas morfologicamente como edifícios vulcânicos (Figura 1). Dentre esses, 17 têm altura relativa superior a $2500 \mathrm{~m}$. No extremo leste da Cadeia, ocorrem Ilhas de Trindade e Martim Vaz. As exposições geológicas dessas ilhas representam perfis horizontais da parte superior dos edifícios vulcânicos, exibindo fluxos de lava, depósitos piroclásticos e condutos vulcânicos (e.g. Almeida 1961. 1965).

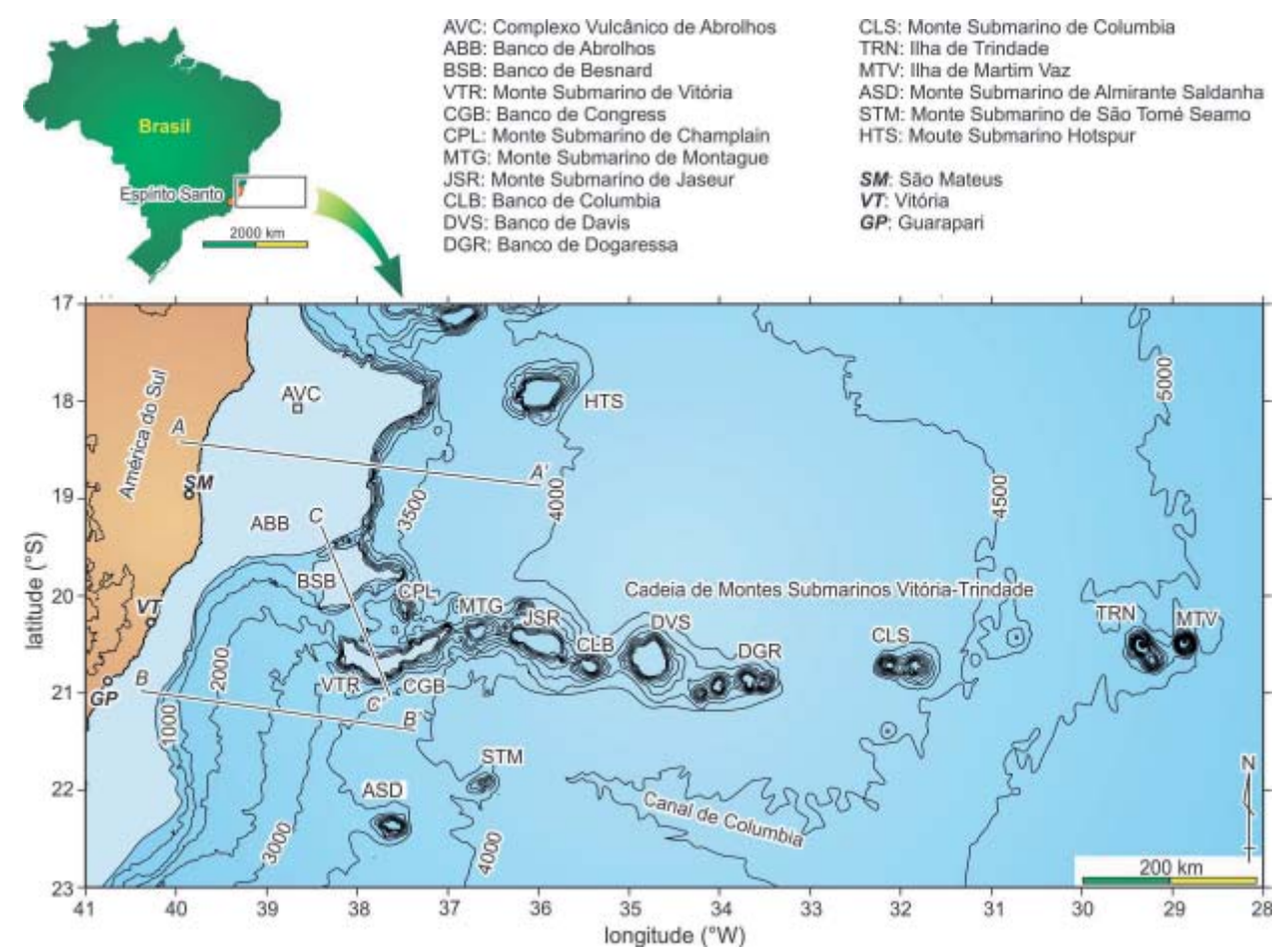

Figura 1 - Mapa batimétrico da área da Cadeia Vitória-Trindade, ES. Os dados topográficos são originados de TOPO elaborado com o auxilio de software original BAZ ver. 1.0. (Motoki \& Motoki, 2011). 
Essas ilhas expõem lavas e diques constituídos por rochas alcalinas ultrabásicas, tais como basanito e ankaramito, com eventuais ocorrências de necks de fonolito (Almeida, 1961; 1965; Ulbrich, 1994; Marques et al., 1999). A maioria das idades radiométricas das amostras da Ilha de Trindade está na faixa entre 2.0 Ma a 3.0 Ma. As idades para a Ilha de Martim Vaz são mais jovens do que 1 Ma (e.g. Cordani, 1970; Valencio \& Mendía, 1974).

As amostras dragadas do Monte Submarino de Columbia, Banco de Dogaressa, Banco de Davis e Monte Submarino de Jaseur são rochas ultrabásicas alcalinas, como picrito e ankaramito (Fodor \& Hanan, 2000; Skolotnev et al., 2010). Até o presente, há apenas duas datações da mesma localidade na encosta nordeste do Banco de Jaseur, indicando a mesma idade, U-Pb de $29.8 \pm 6.6 \mathrm{Ma}$ (Skolotnev et al., 2011).

O desenvolvimento da batimetria predita nos últimos anos possibilitou uma relevante evolução nos estudos geomorfológicos das feições submarinas, inclusive das regiões pelágicas do Brasil (e.g. Sichel et al., 2008; Motoki et al., 2009). Os autores apresentam descrições e análises geomorfológicas da Cadeia Vitória-Trindade com base nos dados do TOPO, da Universidade de Califórnia, San Diego (UCSD), e suas interpretações.

\section{Metodologia}

Os autores adotaram a última versão do TOPO (UCSD-SIO, 2011, ver. 14.1) para a confecção de mapas topográficos da morfologia submarina. Este é o banco de dados de topografia e gravimetria para o fundo do oceano que foi elaborado a partir das análises de variação da órbita de satélite (Smith \& Sandwell, 1997), chamada de batimetria predita. A resolução horizontal aparente é $1.85 \mathrm{~km}$ na região equatorial. Em comparação com a batimetria por multi-feixe, a resolução é baixa, porém cobre uma grande área oceânica na faixa de latitudes entre $72^{\circ} \mathrm{N}$ e $72 \mathrm{~S}^{\circ}$.

A primeira versão do TOPO tinha a resolução aparente de $3.7 \mathrm{~km}$, porém a resolução verdadeira era mais baixa. Através do acúmulo de dados de satélites e de batimetria convencional, aprimoraram-se as resoluções aparente e verdadeira. As versões recentes do TOPO foram aprimoradas por meio dos dados de batimetria por navios, elevando a resolução real dos dados. O aprimoramento na resolução real durante os últimos 5 anos foi notável.

Atualmente, existem alguns bancos de dados de batimetria predita, tais como IBCAO, GINA, J-EGG, JODC, RIDGE, ETOPO2, ETOPO1, TOPO e GEBCO. Dentre esses, o TOPO e do GEBCO são mais utilizados para pesquisas científicas. Os dados do TOPO são distri- buídos gratuitamente pelo Instituto de Oceanografia da Universidade de Califórnia, San Diego (Scripps Institution of Oceanography). Os dados do GEBCO (General Bathymetric Chart of the Oceans) são distribuídos pelo IHO (International Hydrographic Organization), porém os dados completos da última versão não são gratuitos. A versão livre está disponível no Centro de Dados da Oceanografia Britânica (British Oceanographic Data Centre).

O IHO tem dados abundantes de batimetria por navio. Portanto, em determinadas áreas, especialmente nas proximidades de portos, os dados do GEBCO têm resolução superior à do TOPO. Entretanto, nas regiões pelágicas, os mapas batimétricos de ambos são praticamente iguais. Para o presente trabalho, os autores adotaram os dados do TOPO.

Os trabalhos anteriores sobre a Cadeia VitóriaTrindade (e.g. Rangel 1998; Ferrari \& Riccomini, 1999; Marques et al., 1999; Thomás-Filho \& Rodrigues, 1999; Foder \& Hanan, 2000; Lima et al., 2009) utilizavam mapas confeccionados por batimetria convencional de navios, tais como NGDC (National Geophysical Data Center) de 1994 e Atlas Digital GEBCO (IOC-IHD) de 1997. Esses mapas batimétricos eram de baixa resolução, desta forma, o Banco de Dogaressa (DGR, Figura 1) foi expresso como uma única saliência morfológica (Figura 2A).

A introdução dos dados gravimétricos à confecção de mapa batimétrico, tal como Gomes et al. (1997; Relatório interno da PETROBRAS, citado por Rangel, 1998), aprimorou drasticamente a resolução e, o Banco de Dogaressa foi expresso como a saliência morfológica composta de duas elevações. A versão adotada pelos autores tem resolução muito mais elevada (Figura 2B). Skolotnev et al. (2011) também adotou a mesma versão ou similar. Esta versão revela o referido banco como sendo constituído por quatro saliências morfológicas de forma cônica com topos planares de $50 \mathrm{~m}$ de profundidade (Figura 2B).

Para certas análises geomorfológicas, os autores utilizaram técnicas de seppômen e sekkokumen. Seppômen é o mapa topográfico virtual elaborado por preenchimento de vales e drenagens e, o sekkokumen, por remoção de picos e cristas (Figura 3; e.g. Motoki et al., 2008). Os cálculos para seppômen e sekkokumen são realizados com o auxílio do software original BAZ versão 1.0 (Figura 4). As áreas da base e topo planar dos vulcões foram medidas pelo método de contagem de pixels utilizando-se o software original Wilbur versão 1.0 (Motoki et al., 2006; 2007a). 
A. Atlas Digital GEBCO (1997)

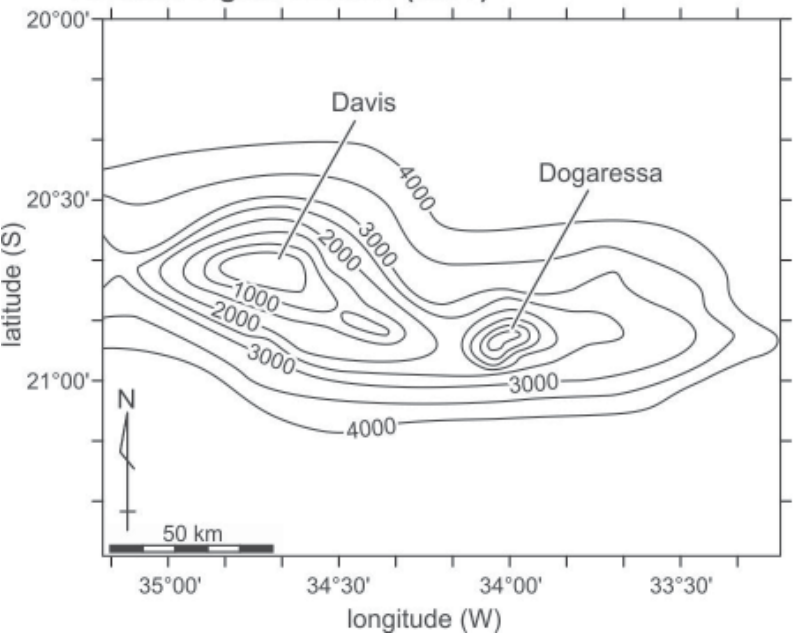

B. TOPO ver. 14.1 (2011) para o presente trabalho

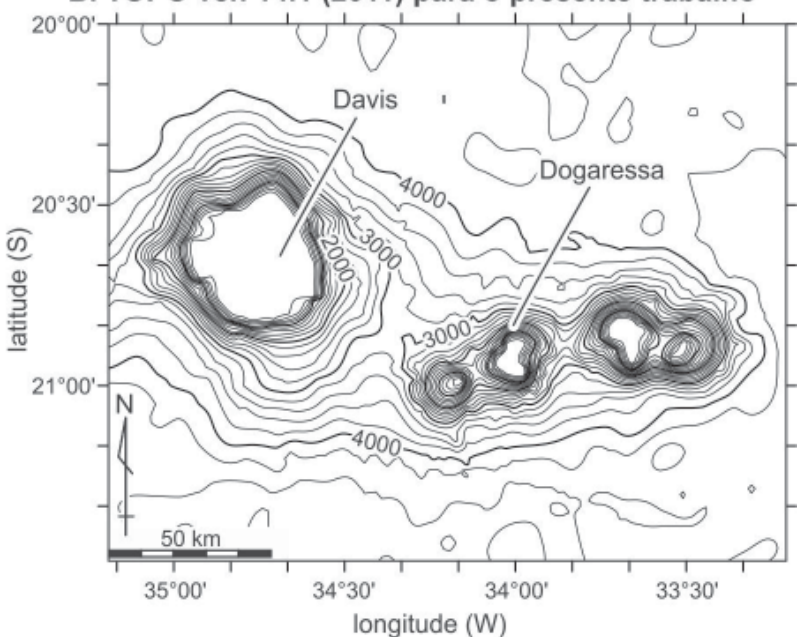

Figura 2 - Comparação dos mapas batimétricos da área em torno do Banco Dogaressa e Banco Davis: A) Atlas digital de GEBCO da versão de 1997 com base na batimetria convencional, que foi utilizado por Ferrari \& Riccomini (1999); B) Batimetria predita com base nos dados do TOPO ver. 14.1 (2011), que é adotada pelos autores no presente trabalho.

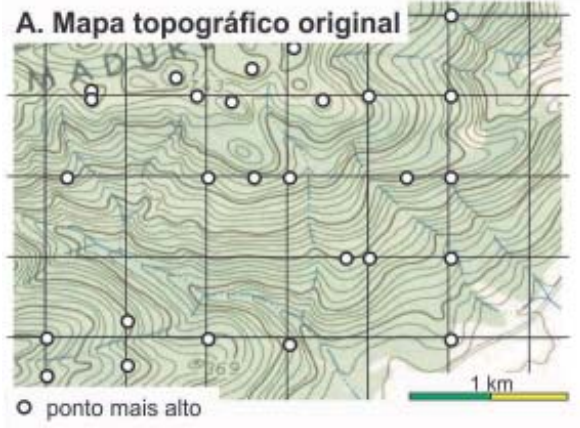

C. Efeito de intervalo da grade

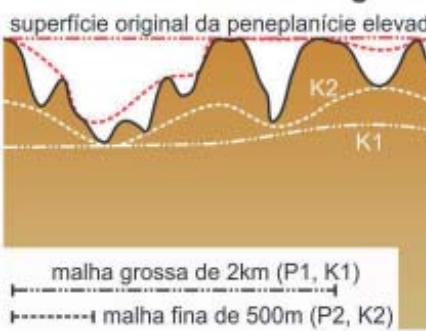

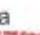

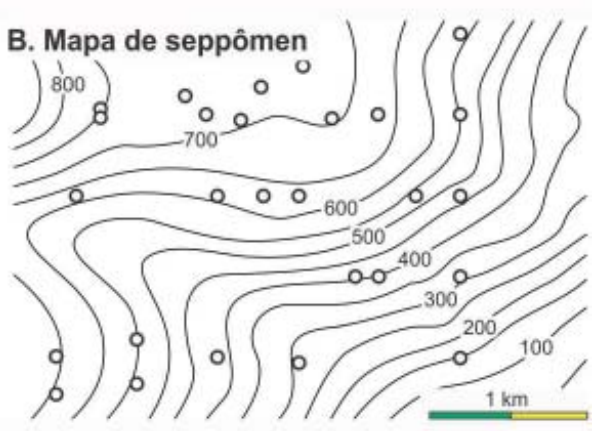

P1, P2 - seppômen

K1, K2 - sekkokumen

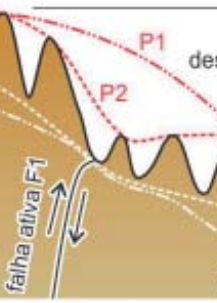

deslocamento vertical da falha ativa deslocamento da peneplanicie elevada
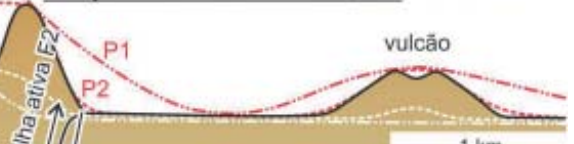

Figura 3 - Ilustração esquemática para o método de confecção de mapa de seppômen $(A, B)$ e para o efeito de intervalo de malha para seppômen e sekkokumen (C), modificado de Motoki et al. (2008). 


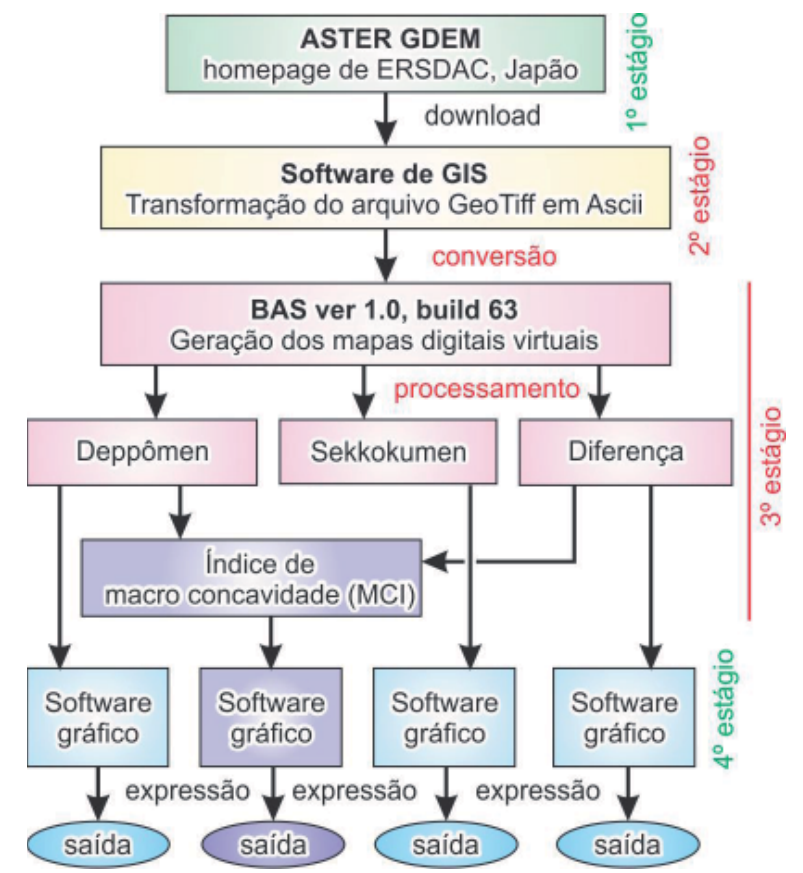

Figura 4 - Fluxograma de funcionamento do sistema BAZ que elabora os dados para os mapas de seppômen, sekkokumen, diferença entre os dois e diagrama de macro concavidade (MCI; Motoki \& Motoki, 2011).

\section{Morfologia do embasamento da margem continental}

O mapa de batimetria predita acima citado tem notável evolução na resolução espacial em comparação com os mapas batimétricos anteriores desta região e demonstrou uma série de novidades geomorfológicas, tanto no embasamento quanto nos edifícios vulcânicos da Cadeia Vitória-Trindade.

A plataforma continental das regiões litorâneas do Estado do Espírito Santo e da Bahia tem extensão muito variável. Entre as latitudes $19^{\circ} 50^{\prime} \mathrm{S}$ e $21^{\circ} 10^{\prime} \mathrm{S}$, próxima à cidade de Vitória, ES, a plataforma continental é estreita, em torno de $40 \mathrm{~km}$ a partir da linha costeira. O talude continental está presente em torno de W39 $50^{\prime}$. Por outro lado, entre as latitudes $\mathrm{S} 17^{\circ} 30^{\prime}$ e $\mathrm{S} 19^{\circ} 20^{\prime}$, na proximidade de São Mateus, ES, a plataforma continental é extensa, com mais de $200 \mathrm{~km}$ da linha costeira. O talude continental situa-se ao longo de W3750' (Figura 1).

O talude continental e elevação continental apresentam um nítido contraste entre as áreas ao norte e ao sul da Cadeia Vitória-Trindade. O talude continental ao norte da Cadeia tem altura de $3200 \mathrm{~m}$ e inclinação de $12^{\circ}$ a $15^{\circ}$ (Figura 5A). Não se observa notável elevação continental. Estes aspectos indicam que a transição entre continente e oceano (COT, continent ocean transition) é simples, não havendo notável afinamento crustal, sendo muito diferentes do platô de São Paulo (Zalán et al., 2011). Esta ideia é apoiada pelo perfil sísmico da região de plataforma continental de Abrolhos. A morfologia submarina indica contato brusco entre a crosta continental e oceânica. Esta estimativa é apoiada pelo perfil sísmico da região de Abrolhos (Figura 5B; Gladczenko et al. 1997) e de Pernambuco-Paraíba (Gomes et al., 2000).

Por outro lado, o perfil da morfologia submarina da região ao sul da Cadeia Vitória-Trindade é caracterizada por talude continental com altura inferior a $1200 \mathrm{~m}$ e declividade menor do que $3.5^{\circ}$. De $1300 \mathrm{~m}$ para $2500 \mathrm{~m}$ de profundidade, ocorre o flanco suave de elevação da margem continental com declividade geral de $0.5^{\circ}$. A superfície dessa elevação continental é caracteristicamente irregular. $\mathrm{Na}$ borda oriental deste flanco, ou seja, no limite entre a elevação continental e a planície abissal, observa-se uma elevação morfológica linear em direção $\mathrm{N} 10^{\circ} \mathrm{E}$ com $40 \mathrm{~km}$ de largura e $150 \mathrm{~km}$ de comprimento com aspecto similar de uma barreira (Figura 5C; Figura 6 , seta B1). A margem oriental desta barreira é delimitada pela escarpa linear com $700 \mathrm{~m}$ de altura. Cerca de $100 \mathrm{~km}$ ao oeste da B1, ou seja, no lado continental, ocorre outra barreira, denominado B2, com $200 \mathrm{~m}$ de altura e $200 \mathrm{~km}$ de comprimento. Observam-se também as barreiras de menor altura em direção paralela. A morfologia submarina aponta que o contato entre a crosta continental e crosta oceânica, a COT, é complexo devido ao afinamento da crosta continental através de falhas escalonares. Esta consideração é consistente com o perfil sísmico do LEPLAC Linha-C da região oceânica de Pernambuco-Paraíba (Figura 5D; Gomes et al., 2000) e Platô de Pernambuco (Kowsmann \& Costa, 1976, citado em Palma, 1984). Considerando os perfis batimétrico e sísmico (Cainelli \& Mohriak, 1998, citado em Mohriak, 2003) da região de São Paulo como o estereótipo, as grandes barreiras, tais como B1 e B2, podem ser atribuídas às saliências da crosta continental ou domos grandes de sal que estão presentes nas saliências da crosta continental (Mohriak, 2008). Os dois exemplos acima citados sugerem que a batimetria predita desta resolução tem uma boa correlação com as estruturas geológicas determinadas pelas pesquisas sísmicas.

\section{Bacia Oceânica do Brasil}

Em torno da Ilha de Trindade e da Ilha de Martim Vaz, existe uma das áreas mais profundas do Oceano Atlântico Sul, denominada Bacia Oceânica do Brasil 
(BOB, Figura 7; Brazil Oceanic Basin, Skolotnev et al., 2011). A profundidade máxima é aproximadamente $5300 \mathrm{~m}$. A bacia oceânica tem cerca de $1000 \mathrm{~km}$ de extensão em norte-sul e $1200 \mathrm{~km}$ em leste-oeste. A borda norte é delimitada pela Cadeia de Ferraz (Cherkis, 1992) e, na borda sul, pela Cadeia Cruzeiro do Sul (Souza, 1991) e pela Elevação do Rio Grande (Oreiro et al., 2008; Mohriak et al., 2010). As Ilhas de Trindade e Martim Vaz estão próximas à borda leste da referida bacia oceânica.

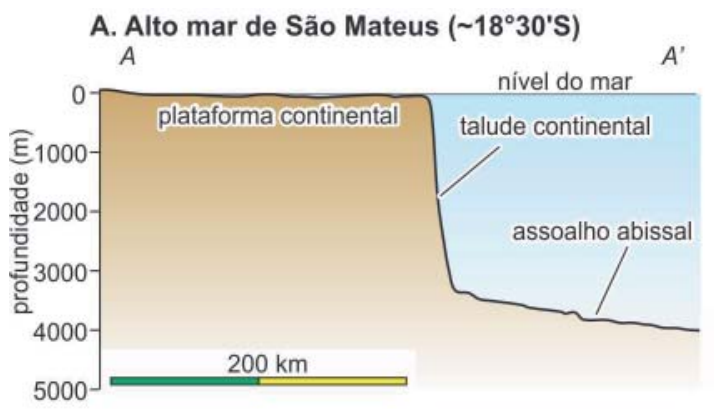

C. Alto mar de Guarapari $\left(\sim 21^{\circ} 15^{\prime} \mathrm{S}\right)$

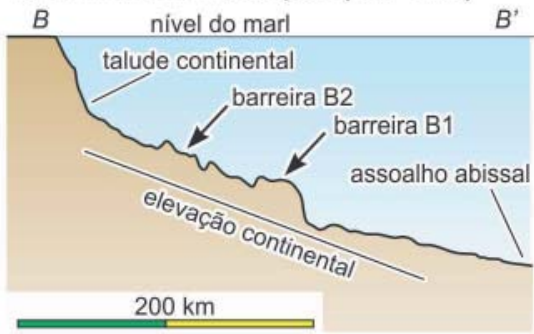

\section{B. Perfil sísmico da região de Abrolhos}

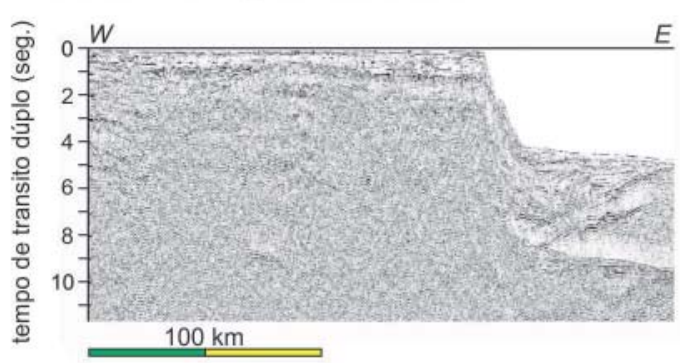

D. Perfil sísmico Pernambuco-Paraíba LEPLAC Linha-C

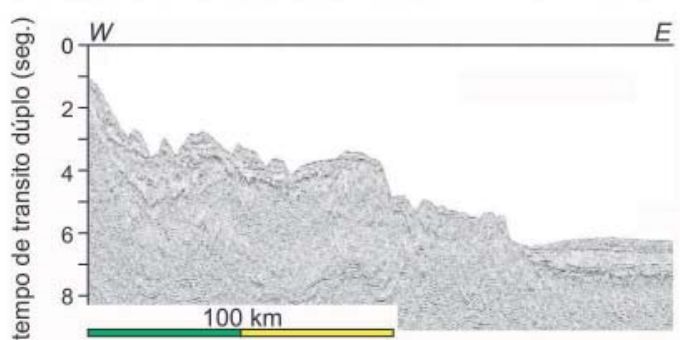

Figura 5 - Perfis batimétricos contrastados da região estudada e sua comparação com dados sísmicos: A) Perfil batimétrico da região norte da Cadeia Vitória-Trindade ao longo de 18³0'S, em torno de São Mateus, ES; B) Perfil sísmico da região de Abrolhos (Gladczenko et al. 1997); C) Perfil batimétrico da região sul da Cadeia Vitória-Trindade ao longo de $21^{\circ} 15^{\prime}$ 'S, em torno de Guarapari, ES; D) Perfil sísmico da região oceânica de Pernambuco-Paraíba ao longo da LEPLAC Linha-C (citado em Gomes et al., 2000 e Mohriak, 2003).

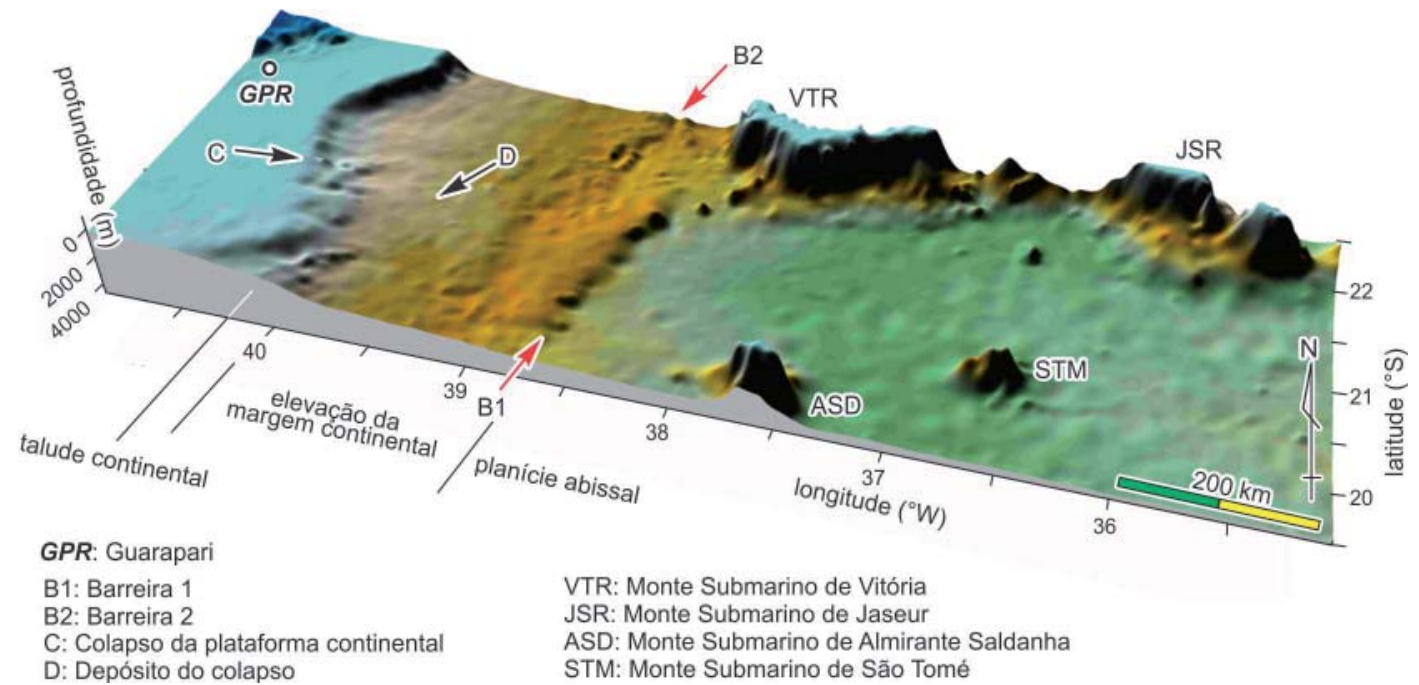

Figura 6 - Mapa de seppômen baseado na malha com intervalo de $3.6 \mathrm{~km}$ para a região ao sul da Cadeia de Montes Submarinos de VitóriaTrindade elaborado com o auxilio de BAZ ver 1.0. Desta forma, os vales submarinos com largura menor do que 3.6km, são virtualmente preenchidos para melhorar a visualização da morfologia. 


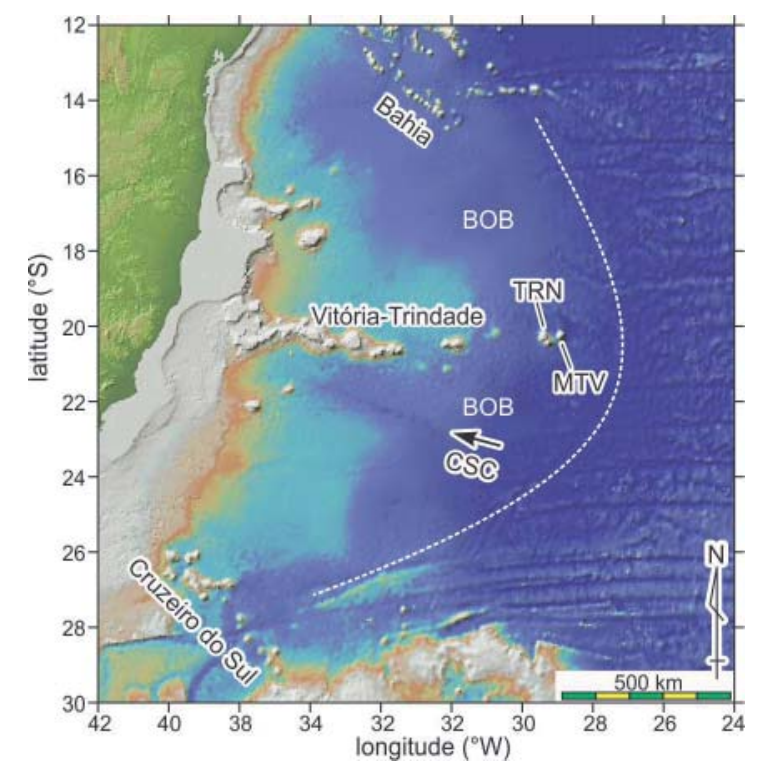

Figura 7 - Mapa de relevo para a região ocidental do Oceano Atlântico Sul apresentando Cadeia Vitória-Trindade e Bacia Oceânica do Brasil (BOB). Os dados batimétricos são originados de Global Multi-Resolution Topography (GMRT) do Serviço Geológico dos Estados Unidos da América (USGS). TRM - Ilha de Trindade; MTV - Ilha de Martim Vaz; CSC - Canal Submarino de Columbia.

A cerca de $200 \mathrm{~km}$ ao sul da Cadeia VitóriaTrindade, ocorre uma depressão morfológica linear em direção de $\mathrm{N} 80^{\circ} \mathrm{W}$ com comprimento de $250 \mathrm{~km}$, largura de $10 \mathrm{~km}$ e profundidade de $400 \mathrm{~m}$, denominada Canal Submarino de Columbia (Figura 7, CSC; Columbia Sea Channel). Esta área é coberta por depósito sedimentar de mais de $1000 \mathrm{~m}$ de espessura. A morfologia atual do canal foi formada pelas correntes de turbidez (Massé et al., 1998) que passaram ao longo do graben estrutural do embasamento (Lima et al., 2009).

\section{Forma geral dos montes submarinos}

A Cadeia Vitória-Trindade é constituída aproximadamente por 30 montes submarinos com altura superior a $1000 \mathrm{~m}$. A maioria desses tem forma cônica, sendo considerados morfologicamente como edifícios vulcânicos de escudo (shield volcano). Dentre esses, Ilha de Martim Vaz (Figura 1, MTV) e Ilha de Trindade (TRN), Monte Submarino de Columbia (CLS), Banco de Dogaressa (DGR), Banco de Davis (DVS) e Monte Submarino de Jaseur (JSR) foram confirmados como vulcões por meio das amostragens e estudos petrológicos (Fodor \& Hanan, 2000; Skolotnev et al., 2010). Os dados novos do TOPO revelaram que Monte Submarino de Columbia, Banco de Dogaressa e Monte Submarino de Jaseur são agregados de mais de um edifício vulcânico.

Os montes submarinos têm forma geral de cone, constituída por elevação no sopé, edifício vulcânico principal e topo planar (Figura 8A). Um vulcão típico tem altura de $4000 \mathrm{~m}$, elevação no sopé de $1000 \mathrm{~m}$ de altura, diâmetro na base de $30 \mathrm{~km}$ e o topo planar com diâmetro de $10 \mathrm{~km}$. A profundidade do topo planar é aproximadamente $50 \mathrm{~m}$ em quaisquer montes submarinos de grande altura da Cadeia Vitória-Trindade. O talude lateral dos edifícios vulcânicos é de alto ângulo, sendo de $15^{\circ}$ a $25^{\circ}$. Dentre esses, as Ilhas de Trindade e Martim Vaz têm edifícios vulcânicos com altura superior a $5000 \mathrm{~m}$ (Figura 8B).
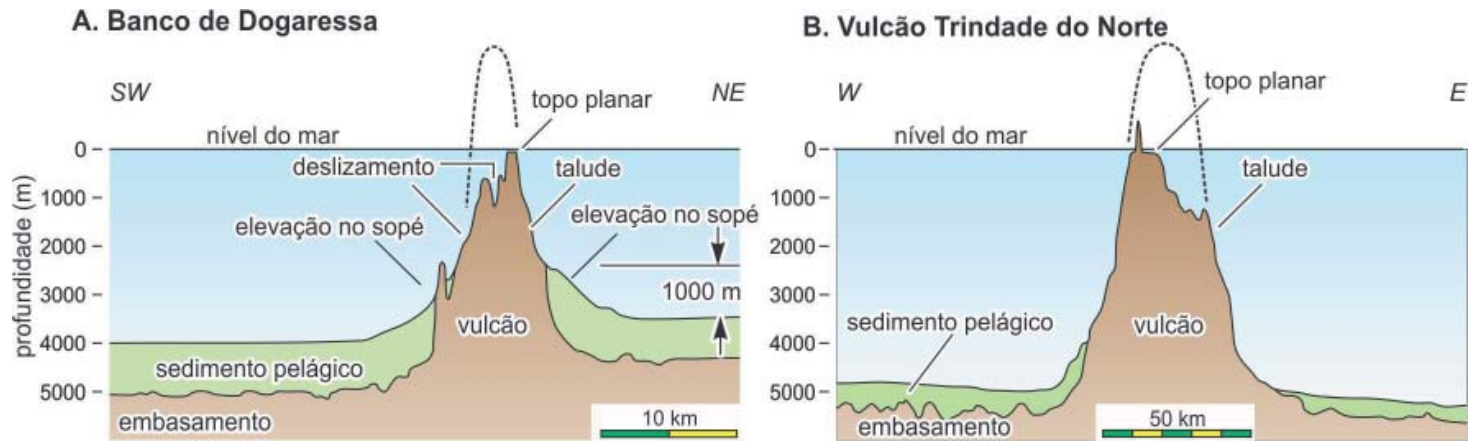

Figura 8 - Perfil geológico dos montes submarinos da Cadeia Vitória-Trindade com base na interpretação dos dados sísmicos por Alves et al. (2006): A) Banco de Dogaressa (DGR), parte central da Cadeia; B) Vulcão Trindade do Norte (TRN-N), extremo leste da Cadeia. 
A grande altura dos vulcões e a extensa área do topo planar sugerem que os montes submarinos formavam ilhas vulcânicas de milhares de metros de altitude original (Figura 8). Isto é, o volume do topo perdido pela erosão de onda do mar pode ser significativamente grande. Entretanto, a parte emersa dos vulcões foi erodida durante o tempo geológico. As idades radiométricas das amostras coletadas da Ilha de Martim Vaz (Cordani, 1970; Valencio \& Mendía, 1974) indicam que a erosão acima citada ocorreu durante um período menor do que um milhão de anos. Os afloramentos da Ilha de Trindade e de Martim Vaz não correspondem ao topo dos vulcões, mas um perfil horizontal da parte superior dos edifícios vulcânicos. A existência de numerosos necks e diques da Ilha de Trindade corroboram esta interpretação.

\section{Descrições dos montes submarinos vulcânicos}

Os edifícios vulcânicos da Cadeia Vitória-Trindade apre- sentam características individuais, tanto da forma original dos vulcões quanto da maneira de erosão por deslizamento.

\section{Ilha de Martim Vaz}

AIlha de Martim Vaz(MTV, Figura 1) está situada na extremidade leste da Cadeia Vitória-Trindade em $20^{\circ} 29^{\prime} \mathrm{S}$ e $28^{\circ} 51^{\prime} \mathrm{W}$. O vulcão tem altura atual de $5100 \mathrm{~m}$ a partir da planície abissal. A base é de $30 \mathrm{~km}$ x $40 \mathrm{~km}$ sendo alongado ligeiramente a $\mathrm{N} 15^{\circ} \mathrm{W}$ (Figura 9A). O talude do edifício vulcânico tem $25^{\circ}$ de declividade e o topo planar tem $8 \mathrm{~km}$ de diâmetro com área medida de $69 \mathrm{~km}^{2}$. Uma pequena parte do topo está emersa formando algumas pequenas ilhas. Não se observa notável morfologia de deslizamento no talude, indicando que o vulcão foi formado recentemente. A elevação no sopé está ausente. As rochas expostas são alcalinas máficas com idades mais jovens do que 1 Ma (Almeida, 1961; 1965; Ulbrich, 1994; Marques et al., 1999).
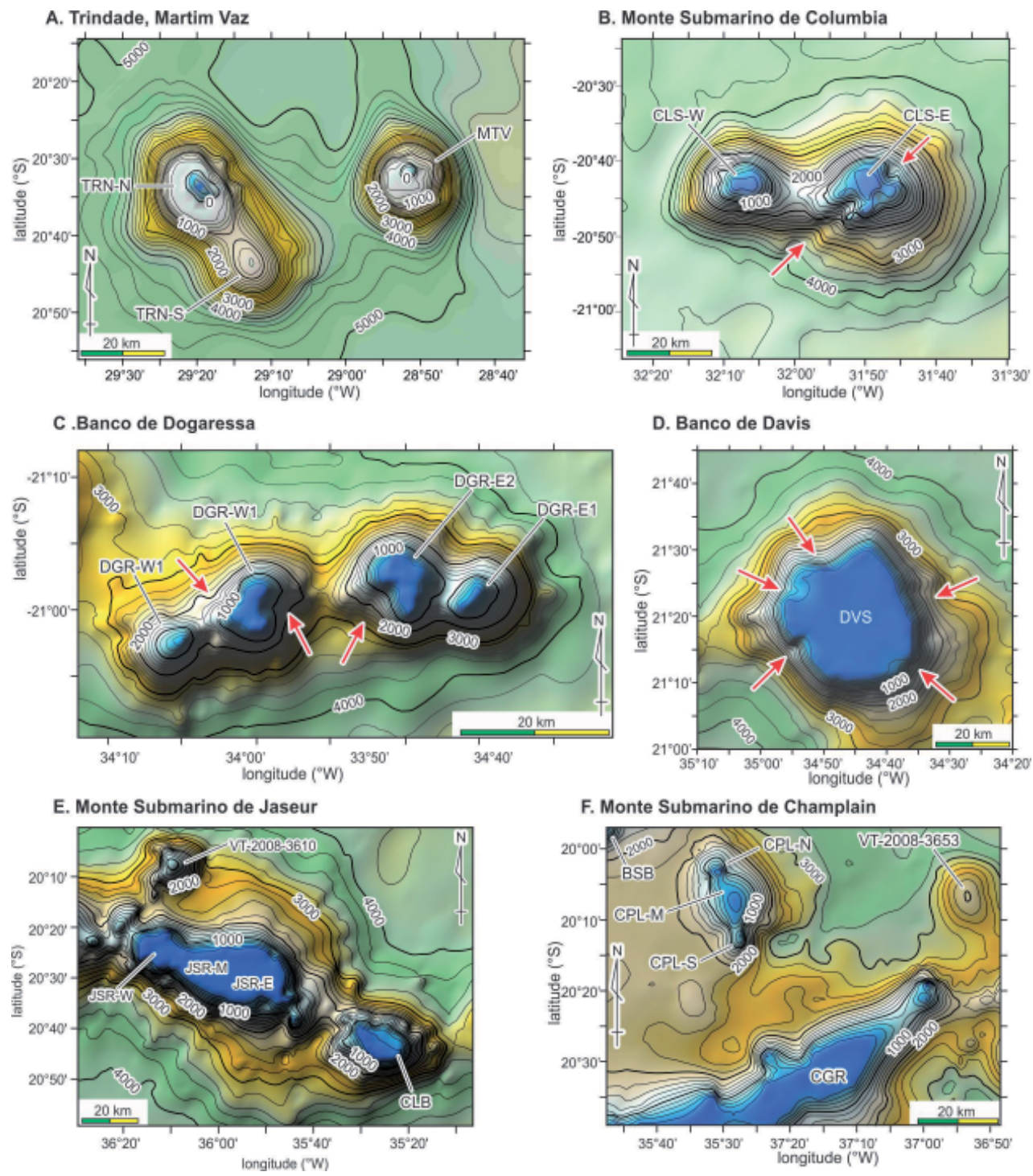

Figura 9 - Morfologia submarina dos vulcões da Cadeia VitóriaTrindade: A) Trindade (TRN-N, TRN-S) e Martins Vaz (MTV); B) Monte Submarino de Columbia $(C L S-E, C L S-W) ; C)$ Banco de Dogaressa (DGR-E1, DGR-E2, $D G R-W 2, D G R-W 1) ; D)$ Banco de Davis (DVS); E) Monte Submarino de Jaseur (JSR-E, JSR-M, JSR-W); F) Monte Submarino de Champlain $(C P L)$. 


\section{Ilha de Trindade}

A Ilha de Trindade situa-se a cerca de $50 \mathrm{~km}$ ao oeste da Ilha de Martim Vaz (Figura 9A). A elevação morfológica é constituída por dois edifícios vulcânicos, que estão posicionados em uma distância de $25 \mathrm{~km}$ a direção $\mathrm{N} 40^{\circ} \mathrm{W}$. O tamanho desses vulcões é comparável com o Vulcão Martim Vaz. O Vulcão Trindade do Norte (TRN-N, Figura 9A) tem $5500 \mathrm{~m}$ de altura atual e sua base tem extensão de $35 \mathrm{~km} \mathrm{x}$ $40 \mathrm{~km}$. O talude é íngreme com ângulo representativo de $25^{\circ}$. O topo planar é de $15 \mathrm{~km} \times 12 \mathrm{~km}$ com área de $174 \mathrm{~km}^{2}$. A Ilha de Trindade situa-se na superfície do topo plano em $20^{\circ} 31^{\prime} \mathrm{S}$ e $29^{\circ} 20^{\prime} \mathrm{W}$. Os necks expostos nesta ilha indicam a formação de domos de lava durante as erupções. As rochas expostas são ricas em $\mathrm{Na}$ e altamente subsaturadas em sílica, tais como nefelinito, basanito, e fonolito com idades em torno de 2.5 Ma (Almeida, 1961; 1965; Cordani, 1970; Marques et al., 1999).

O Vulcão Trindade do Sul (TRN-S) situa-se em $20^{\circ} 43^{\prime} \mathrm{S}$ e $29^{\circ} 27^{\prime} \mathrm{W}$ e tem $4600 \mathrm{~m}$ de altura e base de $30 \mathrm{~km}$ x $30 \mathrm{~km}$, sendo pouco menor do que o Vulcão Trindade o Norte. A declividade do talude é $16^{\circ}$ e a profundidade do topo está em uma profundidade de $500 \mathrm{~m}$. Os deslizamentos no talude são irrelevantes (Figura 9A) e a elevação no sopé não é observada.
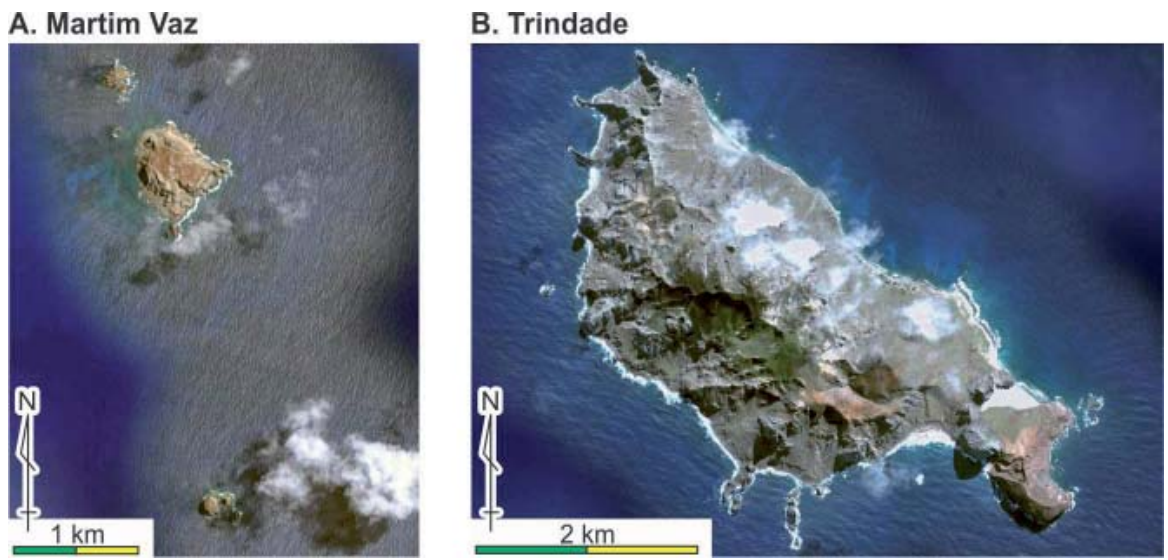

Figura10 - Ilhas vulcânicas da Cadeia de Montes Submarinos de Vitória-Trindade: A) Ilha de Trindade, 20³0.5 'S, $29^{\circ} 19.5^{\prime}$ W; B) Ilha de Martim Vaz, $20^{\circ} 28.5^{\prime}$ 'S, $28^{\circ} 51.1^{\prime}$ W. As fotos são originadas de Google Earth ${ }^{\mathrm{TM}}$.

\section{Montes Submarinos VT-2030-3043 e VT-2031-3059}

Esses pequenos montes submarinos situam-se em torno de $150 \mathrm{~km}$ ao oeste da Ilha de Trindade, em $20^{\circ} 30^{\prime} \mathrm{S}$ e $30^{\circ} 43 \mathrm{~W}$ (SM1, Figura 10) e $21^{\circ} 31^{\prime} \mathrm{S}$ e $30^{\circ} 59^{\prime} \mathrm{W}$ (SM2) e, têm forma cônica. Devido a esses não terem nomes oficiais, neste artigo esses são chamados com base nas coordenadas, respectivamente de VT-2030-3043 e VT2031-3059. O VT-2030-3043 tem 1100m de altura e a base de $45 \mathrm{~km} \times 36 \mathrm{~km}$. A declividade do talude é $4^{\circ}$. Este ângulo é significativamente menor do que os vulcões de Trindade e Martim Vaz. O VT-2131-3059 é situado em cerca de $30 \mathrm{~km}$ a oeste-sudoeste do VT-2030-3043. Este é menor ainda, com $600 \mathrm{~m}$ de altura e $20 \mathrm{~km}$ x $20 \mathrm{~km}$ da base. A declividade do talude é muito suave, aproximadamente de $3^{\circ}$. Não se observam morfologias de deslizamento. O baixo ângulo do talude sugere que estes vulcões não são constituídos por pillow-lava, mas provavelmente por hialoclastito ou tufo.

\section{Monte submarino de Columbia}

O Monte Submarino de Columbia é situado a cerca de $280 \mathrm{~km}$ ao oeste da Ilha de Trindade. Este é constituído por dois edifícios vulcânicos posicionados em direção leste-oeste. Uma única amostra dragada apresenta composição correspondente a ankaramito (Fodor \& Hanan, 2000). O Vulcão Columbia do Leste (CLS-E, Figura 9B) está presente em $20^{\circ} 43 \mathrm{~S}$ e $31^{\circ} 49 \mathrm{~W}$. Este tem $4000 \mathrm{~m}$ de altura, $35 \mathrm{~km} \times 30 \mathrm{~km}$ da base e $6 \mathrm{~km} \times 8 \mathrm{~km}$ de topo planar. A declividade do talude é de alto ângulo, em torno de $16^{\circ}$. Na encosta noroeste observa-se um vale de deslizamento de talude de $800 \mathrm{~m}$ de profundidade, e na encosta noroeste, de $400 \mathrm{~m}$ de profundidade (Figura 9B, setas). A elevação no sopé não é relevante.

O Vulcão Columbia do Oeste (CLS-W) situa-se em $20^{\circ} 43 \mathrm{~S}$ e $32^{\circ} 07^{\prime} \mathrm{W}$, em torno de $30 \mathrm{~km}$ ao oeste do Columbia do Leste. Este vulcão é pouco menor do que o outro, $4000 \mathrm{~m}$ de altura e $25 \mathrm{~km} \times 30 \mathrm{~km}$ da base. A declividade do talude é alta, cerca de $17^{\circ}$, e o topo plano tem extensão de $6 \mathrm{~km}$ x $8 \mathrm{~km}$. Deslizamentos submarinos são pouco expressivos. A elevação no sopé está ausente. O topo planar de ambos os vulcões é raso, sendo em torno de $50 \mathrm{~m}$ de profundidade. 


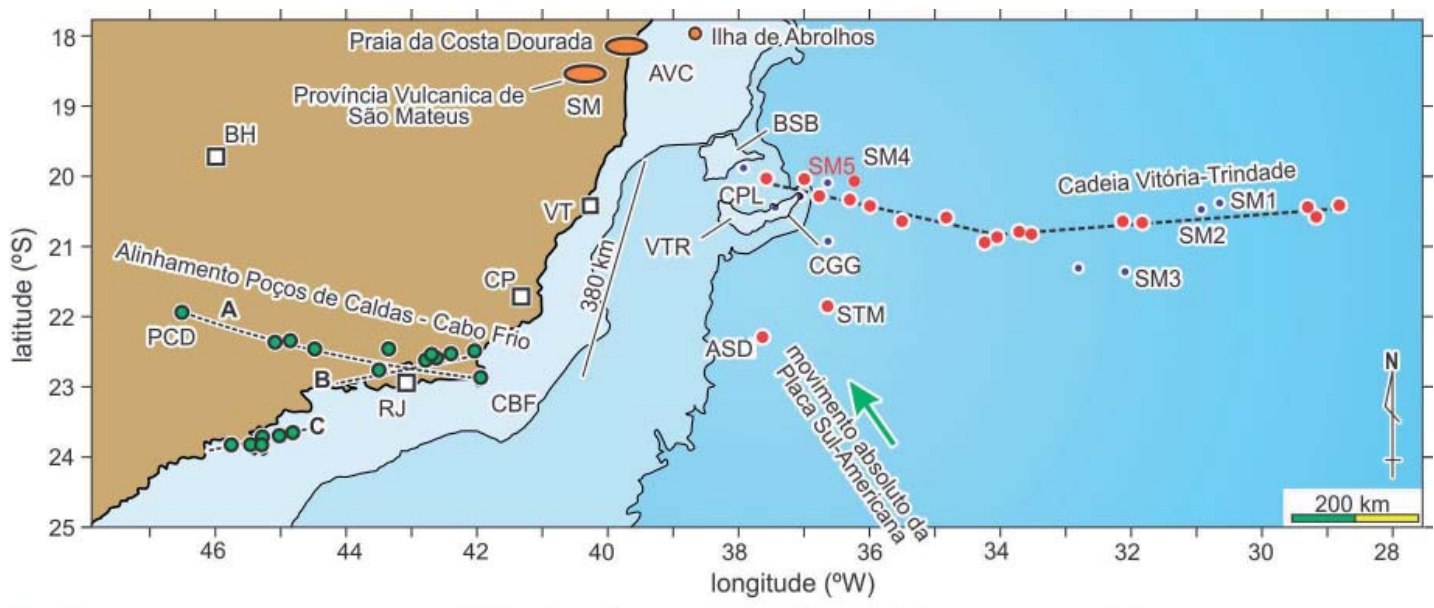

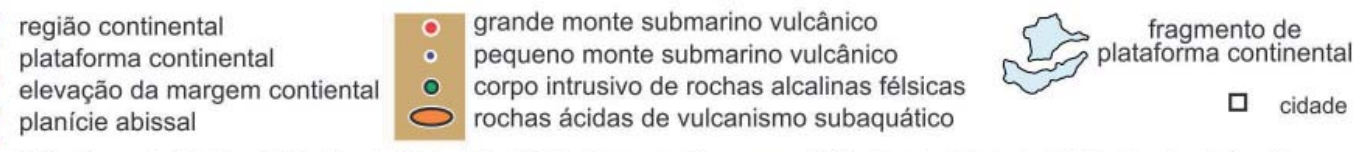
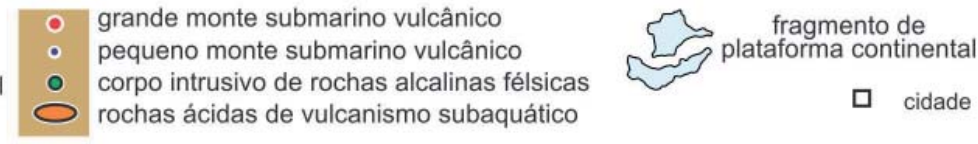

PCD - Poços de Caldas; CBF - Ilha de Cabo Frio; DGR - Banco de Dogaressa; TRN - Itha de Trindade; MTV - Ilha de Martim Vaz; CPL - Monte Submarino de Champlain; ASD - Monte Submarino de Almirante Saudanha; STM - Monte Submarino de São Tomé SM1 SM5 - pequenos vulcōes com altura inferior a $2500 \mathrm{~m}$

BSB - Banco de Besnard; VTR - Monte Submarino de Vitóra; CGB - Banco de Congress

$\mathrm{BH}$ - Belo Horizonte; RJ - Rio de Janeiro; CP - Campos; VT - Vitória

Figura 11 - Magmatismo do Cretáceo ao Cenozóico na borda ocidental do Oceano Atlâtico na proximidade dos Estados do Espírito Santo, Rio de Janeiro e São Paulo, demonstrando Cadeia de Montes Submarinos de Vitória-Trindade, Alinhamento Magmático de Poços de Caldas-Cabo Frio e Província Vulcânica de São Mateus. O movimento da placa é relativo aos hot-spots do mundo $\left(O^{\prime} C o n n o r ~ \& ~ R o e x\right.$, 1992; Steinberger, 2000).

\section{Monte Submarino VT-2123-3207}

Este pequeno monte submarino ocorre a cerca de $70 \mathrm{~km}$ ao sul do Vulcão Columbia do Oeste, em $21^{\circ} 23^{\prime} \mathrm{S}$ e $32^{\circ} 07^{\prime} \mathrm{W}$ (SM3, Figura 11). Esta localidade é pouco distante da Cadeia Vitória-Trindade. Esta feição tem $1100 \mathrm{~m}$ de altura, $30 \mathrm{~km}$ de diâmetro na base e, a declividade do talude é baixa, $5^{\circ}$. O topo está a $3500 \mathrm{~m}$ de profundidade.

\section{Banco de Dogaressa}

O Banco de Dogaressa (DGR, Figura 1,9C) está presente a aproximadamente $200 \mathrm{~km}$ ao oeste do Monte Submarino de Columbia. A batimetria predita revelou que este é constituído por quatro edifícios vulcânicos alinhados em direção leste-oeste. De leste para oeste, tais edifícios são chamados respectivamente de Dogaressa do Leste 1, Leste 2, Oeste 2 e Oeste 1 (DGR-E1, DGR-E2, DGR-W2, DGRW1, Figura 9C) e situados respectivamente em $20^{\circ} 59^{\prime} \mathrm{S}$ e $34^{\circ} 45^{\prime} \mathrm{W}, 20^{\circ} 58^{\prime} \mathrm{S}$ e $33^{\circ} 50^{\prime} \mathrm{W}, 21^{\circ} 00^{\prime} \mathrm{S}$ e $34^{\circ} 00 \mathrm{~W}, 21^{\circ} 02^{\prime} \mathrm{S}$ e $34^{\circ} 05 \mathrm{~W}$. Os vulcões são de $4000 \mathrm{~m}$ de altura incluindo a elevação no sopé. A base desses é, respectivamente, de $17 \mathrm{~km} \times 15 \mathrm{~km}, 20 \mathrm{~km} \times 15 \mathrm{~km}, 15 \mathrm{~km} \times 13 \mathrm{~km}$ e $12 \mathrm{~km} \mathrm{x}$ $14 \mathrm{~km}$, o topo planar é de $3 \mathrm{~km}$ x $1 \mathrm{~km}, 8 \mathrm{~km} \times 5 \mathrm{~km}, 7 \mathrm{~km}$ x $5 \mathrm{~km}$ e $1 \mathrm{~km}$ x $1 \mathrm{~km}$ e, o ângulo do talude é de $26^{\circ}, 27^{\circ}$, $28^{\circ}$ e $24^{\circ}$. As amostras dragadas apresentam composição picrítica (Skolotnev et al., 2010). A elevação no sopé é relevante, com altura de $1000 \mathrm{~m}$, extensão horizontal de $10 \mathrm{~km}$ e declividade máxima de $7^{\circ}$. Observam-se os vales de deslizamento do talude dos edifícios vulcânicos com profundidade maior do que $200 \mathrm{~m}$ (Figura 9C, setas).

\section{Banco de Davis}

O Banco de Davis (DVS, Figura 9D) situa-se a cerca de $70 \mathrm{~km}$ ao oeste-noroeste do Vulcão DGR-W1, em $21^{\circ} 20^{\prime} \mathrm{S}$ e $34^{\circ} 45^{\prime} \mathrm{W}$ (Figura 1). Este vulcão tem $4000 \mathrm{~m}$ de altura com forma circular. A base tem $60 \mathrm{~km}$ de diâmetro e o topo planar possui $35 \mathrm{~km}$ de diâmetro com área de $872 \mathrm{~km}^{2}$, que é muito maior do que outros edifícios vulcânicos. Considerando o tamanho muito grande, esse pode ser um edifício composto de mais de um vulcão. O talude é de alto ângulo, de $20^{\circ}$ a $25^{\circ}$. Em certas localidades a declividade é maior do que $30^{\circ}$. A elevação no sopé tem $1400 \mathrm{~m}$ de altura e $20 \mathrm{~km}$ de extensão com $5^{\circ}$ de declividade. As morfologias de deslizamento submarino são expressivas. 


\section{Banco de Columbia}

O Monte Submarino Columbia (CLB, Figura 1) situa-se em $20^{\circ} 44^{\prime} \mathrm{S}$ e $35^{\circ} 26^{\prime} \mathrm{W}$, aproximadamente $75 \mathrm{~km}$ ao oeste-sudoeste do Banco de Davis. O vulcão tem $4000 \mathrm{~m}$ de altura, 15 x $8 \mathrm{~km}$ de topo planar e $17^{\circ}$ de declividade no talude (Figura 9E). A elevação no sopé tem $1000 \mathrm{~m}$ de altura e $20 \mathrm{~km}$ de extensão com $3^{\circ}$ de declividade. Na encosta nordeste, observam-se numerosas morfologias de deslizamento submarino.

\section{Monte Submarino de Jaseur}

O Monte Submarino Jaseur (JSR, Figura 1) é caracterizado por grande área de topo planar, com comprimento de $60 \mathrm{~km}$ e largura de $20 \mathrm{~km}$, sendo alongado em oestenoroeste. Este é situado em $23^{\circ} 30^{\prime} \mathrm{S}$ e $36^{\circ} 00^{\prime} \mathrm{W}$ a cerca de $80 \mathrm{~km}$ a oeste-noroeste do Banco de Columbia. O monte submarino não tem forma cônica, sugerindo que este é constituído por, pelo menos, 3 edifícios vulcânicos de $4000 \mathrm{~m}$ de altura e $30 \mathrm{~km}$ a $40 \mathrm{~km}$ de diâmetro na base. De leste para oeste, são chamados de Jaseur do Leste (JSR-E), Jaseur do Meio (JSR-M) e Jaseur do Oeste (JSR-W). A declividade típica do talude destes é, respectivamente, $17^{\circ}$, $16^{\circ}$ e $20^{\circ}$. A elevação no sopé é destacadamente grande, com a altura de $2000 \mathrm{~m}$, a extensão $70 \mathrm{~km}$ e a declividade de $2^{\circ}$. As morfologias de deslizamento submarino são relevantes.

O trecho entre Banco de Dogaressa (DGR) e Monte Submarino Jaseur (JSR) corresponde à parte central da Cadeia Vitória-Trindade e o magmatismo e o tectonismo associado são intensos.

\section{Monte Submarino de Montague}

O Monte Submarino de Montague (MTG, Figura 1) está presente em $20^{\circ} 23^{\prime} \mathrm{S}$ e $37^{\circ} 39^{\prime} \mathrm{W}$, a cerca de $50 \mathrm{~km}$ a oeste do Vulcão JSR-W, com $4000 \mathrm{~m}$ de altura, $30 \mathrm{~km}$ x $50 \mathrm{~km}$ de base, $18 \mathrm{~km}$ x $10 \mathrm{~km}$ de topo planar e $17^{\circ} \mathrm{de}$ declividade do talude. A elevação no sopé tem $1200 \mathrm{~m}$ de altura, $30 \mathrm{~km}$ de extensão e $2.5^{\circ}$ de ângulo. Os deslizamentos no talude são notáveis. Observam-se duas elevações morfológicas cônicas na lateral leste e uma na lateral oeste, com alturas variando de 600 a $1200 \mathrm{~m}$. Esses podem ser pequenos vulcões.

\section{Montes Submarinos VT-2008-3610 e VT-2008-3653}

Trata-se de pequenos montes submarinos, que correspondem respectivamente a SM4 e SM5 (Figura 11).
O VT-2008-3610 ocorre em $20^{\circ} 08^{\prime} \mathrm{S}$ e $36^{\circ} 10^{\prime} \mathrm{S}$ a cerca de $30 \mathrm{~km}$ a norte do Monte Submarino Jaseur do Oeste e $60 \mathrm{~km}$ a oeste-noroeste do Monte Submarino Montague. Este tem $2600 \mathrm{~m}$ de altura e $25 \mathrm{~km}$ de diâmetro na sua base. $\mathrm{O}$ talude tem declividade relativamente suave, em torno de $10^{\circ}$. Observam-se três grandes deslizamentos submarinos de $200 \mathrm{~m}$ a $400 \mathrm{~m}$ de profundidade. O VT-2008-3653 está presente em $20^{\circ} 08^{\prime} \mathrm{S}$ e $36^{\circ} 53^{\prime} \mathrm{W}$, a cerca de $35 \mathrm{~km}$ a noroeste do Vulcão Montague. Este possui $1400 \mathrm{~m}$ de altura e $25 \mathrm{~km}$ de diâmetro na base. A declividade típica do talude é $7^{\circ}$. Não se observam deslizamentos submarinos.

\section{Monte Submarino de Champlain}

O Monte Submarino Champlain (CMP, Figura 9F) está na extremidade oeste da Cadeia Vitória-Trindade, situado em $20^{\circ} 08^{\prime} \mathrm{S}$ e $30^{\circ} 28^{\prime} \mathrm{W}$ a cerca de $90 \mathrm{~km}$ a oeste-noroeste do vulcão Montague. É constituído por 3 vulcões, do norte para o sul, chamados respectivamente de Champlain do Norte (CMP-N), Champlain do Meio (CMP-M) e Champlain do Sul (CMP-S; Figura 9F). O Vulcão Champlain do Meio tem 2800 m de altura e $20 \mathrm{~km}$ de diâmetro na base. O ângulo típico do talude é $14^{\circ}$. O Vulcão Champlain do Norte e Champlain do Sul possuem $2000 \mathrm{~m}$ de altura e $10 \mathrm{~km}$ de diâmetro na base.

\section{Monte Submarino de Almirante Saldanha e de São Tomé}

Os referidos montes submarinos estão presentes em locais afastados da Cadeia Vitória-Trindade, a cerca de $200 \mathrm{~km}$ a sul (Figura 1). Apesar de não serem membros da Cadeia Vitória-Trindade, esses podem ser importantes sob ponto de vista da gênese do magma. O Monte Submarino de Almirante Saldanha Marinho (Saldanha Seamount, segundo o IHO) ocorre em $22^{\circ} 22^{\prime} \mathrm{S}$ e $37^{\circ} 36^{\prime} \mathrm{W}$, a cerca de $350 \mathrm{~km}$ ao leste de Campos do Estado do Rio de Janeiro. O edifício vulcânico é ligeiramente alongado na direção leste-oeste com 3800m de altura, $35 \mathrm{~km} \times 50 \mathrm{~km}$ da base e $15 \mathrm{~km} \mathrm{x} 10 \mathrm{~km}$ to topo planar (Figura 12A). A declividade do talude é $18^{\circ}$. A profundidade do topo planar é em torno de $50 \mathrm{~m}$, sendo a mesma dos vulcões submarinos da Cadeia VitóriaTrindade. A elevação no sopé está ausente. Na encosta sudoeste, há um vale de deslizamento submarino com $600 \mathrm{~m}$ de profundidade. 

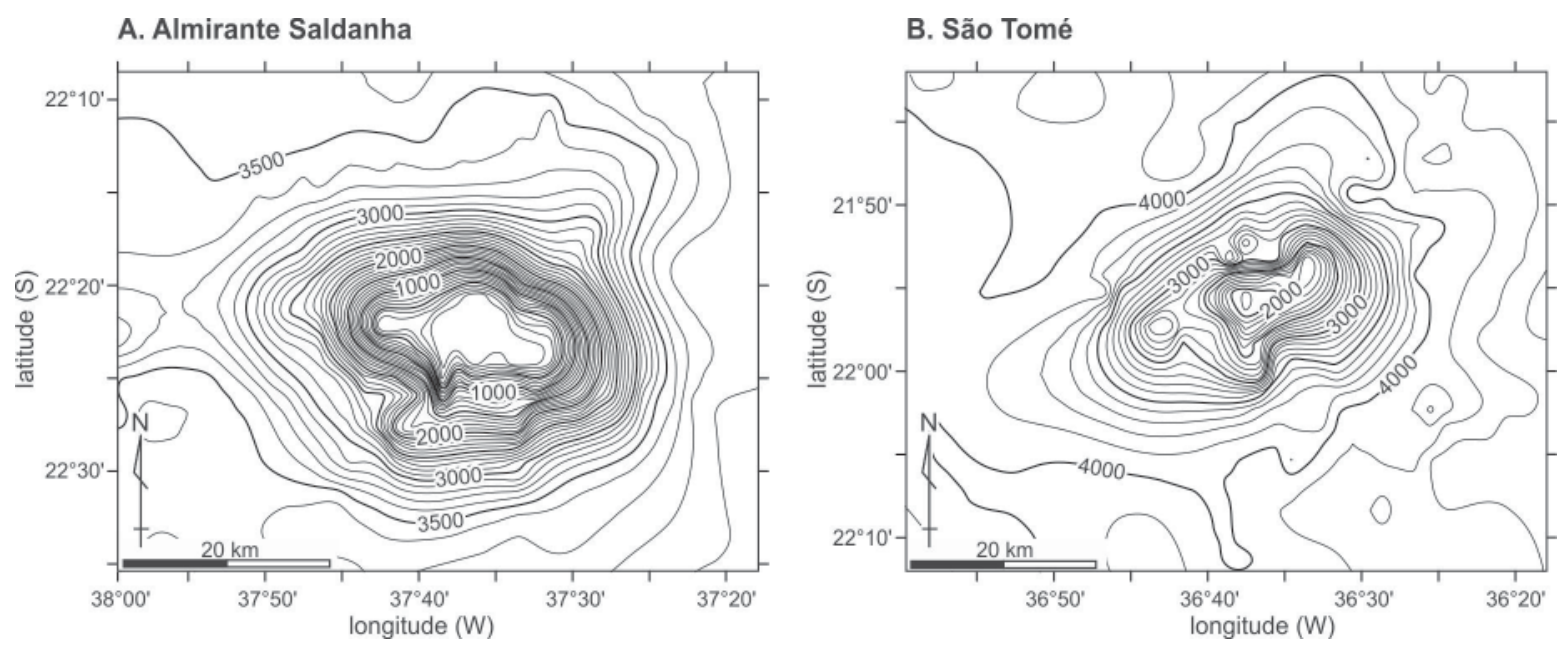

Figura 12 - Morfologia dos montes submarinos situados ao sul da Cadeia Vitória-Trindade: A) Monte Submarino de Almirante Saldanha (ASD); B) Monte Submarino de São Tomé (STM).

O Monte Submarino de São Tomé situa-se em S21 ${ }^{\circ} 56^{\prime}$ e W36 $37^{\circ}$, aproximadamente a $120 \mathrm{~km}$ a leste-nordeste do Vulcão Almirante Saldanha Marinho. Sua altura é 3000m e a base é de $25 \mathrm{~km}$ x $50 \mathrm{~km}$, sendo alongado em WNW-ESSE (Figura 12B). A declividade do talude é cerca de $14^{\circ}$. O monte submarino é constituído por dois vulcões. O topo do vulcão mais alto está a $1800 \mathrm{~m}$ de profundidade e o vulcão mais baixo, a $2600 \mathrm{~m}$ de profundidade. Não há elevação no sopé. Ocorrem 3 vales grandes de deslizamento com 500m de profundidade.

No presente momento, não há amostras obtidas desses montes submarinos e, portanto as rochas constituintes ainda não foram determinadas, seja álcali olivina basalto, comum em vulcões de hot-spot, seja nefelinito, basanito e ankaramito, características da Cadeia Vitória-Trindade.

\section{Características geomorfológicas da Cadeia Vitória- Trindade}

Os montes submarinos vulcânicos da Cadeia VitóriaTrindade, especialmente os 17 vulcões com altura superior a $2500 \mathrm{~m}$, formam uma sequência linear de alta convergência (Figura 11). Na parte central da Cadeia, em torno da coordenada de $\mathrm{W} 34^{\circ}$, observa-se uma inflexão de $18^{\circ}$, que divide a Cadeia vulcânica em dois trechos: 1) Trecho oriental com direção $\mathrm{N} 85^{\circ} \mathrm{E}$; 2) Trecho ocidental de $\mathrm{N} 77^{\circ} \mathrm{W}$. Ao oeste do trecho ocidental, em uma distância de $350 \mathrm{~km}$, ocorre a Província Vulcânica de São Mateus do Estado do Espírito Santo sobre a linha de extensão da Cadeia Vitória-Trindade (Motoki et al., 2007b; Novais et al., 2007). Entretanto, a referida província vulcânica, junto com a ocorrência de riolito piroclástico na Praia da Costa Dourada, Estado da Bahia (Oliveira, informação pessoal), é caracterizada por erupções subaquáticas de riolito piroclástico com a idade Ar-Ar a laser-spot para um cristal de biotita de $69.4 \pm 1.3 \mathrm{Ma}$ (Szatmari \& Novais, 2010, informação pessoal), e não, rochas ultrabásicas. A fusão da crosta continental pelo magma nefelinítico, basanítico ou ankaramítico é uma possibilidade. Na plataforma continental de Abrolhos (ABB, Figura 1), ocorre o Complexo Vulcânico de Abrolhos (AVC, Figura 1, 11) com as idades de 40Ma a $60 \mathrm{Ma}$ (Mohriak et al., 2005). É possível que na plataforma continental de Abrolhos (ABB) e sua extensão ao Banco de Besnard (BSB), ocorram extensos vulcanismos submarinos e o magmatismo da Ilha de Abrolhos é apenas uma manifestação desses (Mohriak, informação pessoal).

Os trabalhos anteriores consideraram que a Cadeia Vitória-Trindade é um alinhamento magmático originado de hot-spot (hot-spot track; e.g. Hertz, 1977; Fodor \& Hanan, 2000). Thomáz-Filho \& Rodrigues (1999) consideraram que a Cadeia Vitória-Trindade e o Alinhamento magmático de rochas alcalinas de Poços de Caldas e Cabo Frio como uma sequência contínua de cadeia de hot-spot. Desta forma, esses autores interpretaram que a idade dos montes submarinos da Cadeia Vitória-Trindade aumenta gradativamente de leste para oeste. Esta idéia é apoiada pelas duas datações de uma mesma localidade do Banco de Jaseur, 29.8 \pm 6.6 Ma (Skolotnev et al., 2011).

Além disso, a Cadeia Vitória-Trindade é de direção leste-oeste e, o vetor do movimento absoluto da Placa SulAmericano é N35W (O’Connor \& Roex, 1992; Steinberger, 2000). Esta controvérsia inviabiliza a idéia de hot-spot track tanto para a Cadeia Vitória-Trindade quanto para o Alinhamento magmático de Poços de Caldas-Cabo Frio (Figura 11; Skolotnev et al., 2010). O movimento absoluto das placas corresponde ao movimento da placa relativo aos principais hot-spots do mundo, conforme o modelo de Morgan (1971; 1972; 1978). A grande diferença entre o movimento absoluto ao noroeste e o movimento relativo ao oeste é uma carac- 
terística da Placa Sul-Americana. Em adição, Skolotnev et al. (2010) opinaram que os magmatismos e os tectonismos associados no trecho entre Banco de Dogaressa e Monte Submarino Jaseur são simultâneos.

No talude dos edifícios vulcânicos, ocorre constante acumulação de depósito pelágico de carbonatos. Quando este chega ao limite da estabilidade da encosta, ocorre o des- lizamento pelo próprio peso (Figura 13). No Vulcão Martim Vaz, Trindade do Sul e Trindade do Norte, não se observa morfologia de deslizamento (Figura 9A). De leste ao oeste da Cadeia Vitória-Trindade, as morfologias do deslizamento tornam-se mais relevantes (Figura 9B, C, D, E). Esta observação indica que os vulcões desta cadeia tendem a serem mais velhos ao oeste.

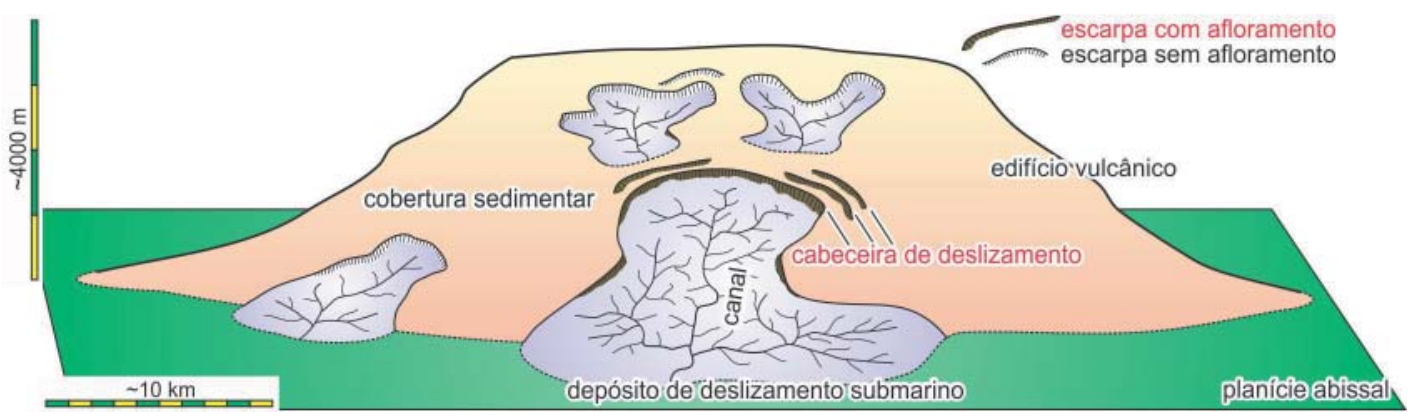

Figura 13 - Ilustração esquemática para o deslizamento submarino de depósitos pelágicos carbonáticos acumulados no talude de um edificio vulcânico submarino. Considera-se que os deslizamentos são de tamanho menor e de frequência maior do que esta ilustração.

Dentre os edifícios vulcânicos da Cadeia VitóriaTrindade, Ilhas de Trindade, Ilha de Martim Vaz e Banco de Jaseur têm dados geocronológicos. A distância entre a Ilha de Trindade e de Martim Vaz é de $50 \mathrm{~km}$ e a diferença de idades entre as duas está em torno de 2 milhões de anos. O Vulcão Martim Vaz é mais jovem do que 1Ma milhões de anos e, portanto não se descarta a possibilidade de erupção. Neste momento, não há indícios observados de erupção. A diferença das idades radiométricas entre as ilhas acima citadas sugere que a fonte de magma se deslocou de oeste para leste a uma velocidade de $2.5 \mathrm{~cm} /$ ano e, atualmente está presente abaixo da Ilha de Martim Vaz. Se esta tendência tem continuado desde o Eocenozóico até o presente, pode-se estimar a idade do Banco de Dogaressa como 20Ma e do Monte Submarino de Champlain como 40Ma. Esta estimativa converge com as idades e as posições geográficas da Província Vulcânica de São Mateus e do Complexo Vulcânico de Abrolhos (Figura $11)$.

Os montes submarinos da parte central da Cadeia Vitória-Trindade têm elevação no sopé bem desenvolvida. O Monte Submarino de Jaseur possui a maior elevação no sopé, com $2000 \mathrm{~m}$ de altura e $70 \mathrm{~km}$ de extensão horizontal. Por outro lado, os vulcões do trecho oriental têm elevação no sopé irrelevante. Em adição, a frequência dos vulcões diminui significativamente ao leste. Essas observações indicam que a intensidade do magmatismo e tectonismo associado diminuem de oeste para leste na Cadeia Vitória-Trindade.

O ângulo do talude dos vulcões acima citados apresenta distribuição bi-modal: 1) Mais íngreme, em torno de $20^{\circ}$; 2) Mais suave, cerca de $7^{\circ}$. Esta diferença pode ser atribuída aos materiais constituintes dos edifícios vulcânicos. Isto é, o talude de alto ângulo é constituído provavelmente por derrames de pillow-lava e o de baixo ângulo, por hialoclastito.

Nas cadeias vulcânicas formadas por hot-spot, observa-se geralmente a subsidência gradativa do assoalho oceânico por tempo (e.g. McNutt, 1984; Quilty, 2001). Entretanto, os topos planares dos vulcões da Cadeia VitóriaTrindade (Figura 14) têm profundidade constante de em torno de $50 \mathrm{~m}$. Isto é, não se observa a subsidência da base dos vulcões da Cadeia Vitória-Trindade.

\section{Desintegração da plataforma continental}

O Banco de Besnard (Figura 1; BSB), Monte Submarino de Vitória (VTR) e Banco de Congress (CGB) estão presentes ao oeste da Cadeia Vitória-Trindade na proximidade com a plataforma continental Abrolhos (ABB). Esses têm notáveis diferenças morfológicas com os montes submarinos de edifícios vulcânicos, como por exemplo, a forma não é cônica e o topo planar tem extensão muito grande.

O Banco de Besnard (BSB, Figura 1) tem forma semiquadrada com o tamanho de $110 \mathrm{~km} \times 80 \mathrm{~km}$ e o topo planar tem área total de $2430 \mathrm{~km}^{2}$. O Monte Submarino de Vitória (VTR) e o Banco de Congress (CGB) estão ligados, formando um banco composto, com comprimento total de $150 \mathrm{~km}$ e largura de $30 \mathrm{~km}$. O topo planar tem área total de $1420 \mathrm{~km}^{2}$ (Figura 15). Esses bancos têm o topo planar incomparavelmente maior do os edifícios vulcânicos. Por exemplo, o Vulcão Trindade do Norte tem o topo planar de $174 \mathrm{~km}^{2}$. 


\section{A. Banco de Davis}

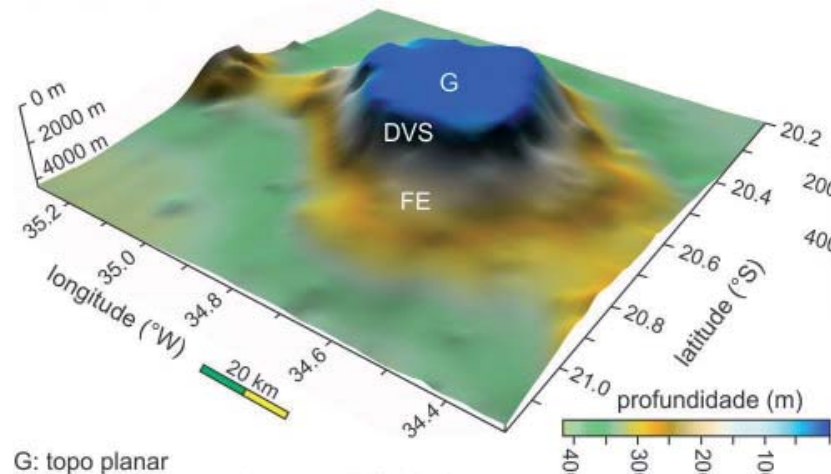

B. Banco de Dogaressa

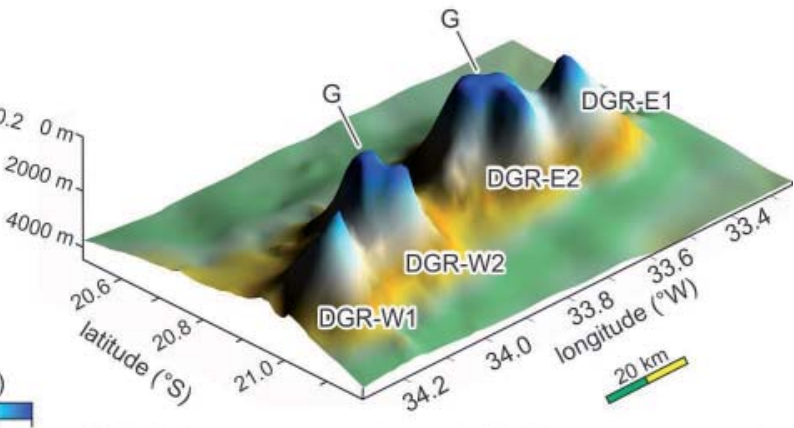

DGR-W1: Dogaressa do oeste 1 DGR-E1: Dogaressa do leste 1 - DGR-W2: Dogaressa do oeste 2 DGR-E2: Dogaressa do leste 2

Figura 14 - Edificios vulcânicos com topo planar da Cadeia Vitória-Trindade: A) Banco de Davis; B) Banco de Dogaressa.

Os bancos acima citados têm o ângulo de talude com declividade bi-modal. Os taludes de baixo ângulo têm declividade de $3^{\circ}$ a $5^{\circ}$ (Figura 15, setas 2 5), e os de alto ângulo, de $20^{\circ}$ a $30^{\circ}$ (setas 6 8). Os taludes de alto ângulo possuem similaridades morfológicas com o talude continental da área pelágica de São Mateus (Figura 5A) e os taludes de baixo ângulo são comparáveis com aquela de Vitória (Figura 5C).
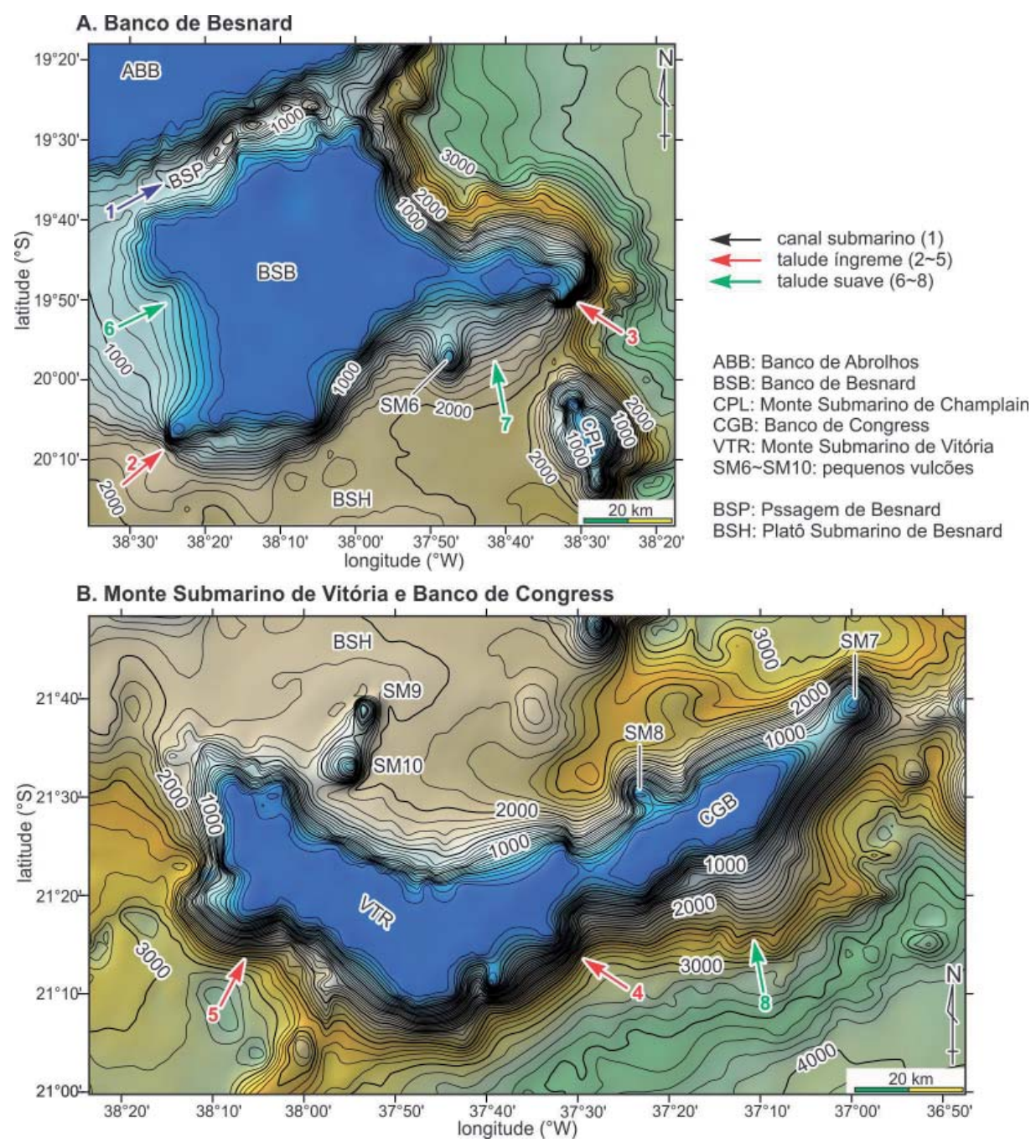

Figura 15 - Morfologia submarina de montes submarinos considerados como fragmentos da plataforma continental com base nas características morfológicas: A) Banco de Besnard (BSB); B) Monte Submarino de Vitória (VTR) e Banco de Congress (CGB). 
O Banco de Besnard (BSB) está em contato com a plataforma continental de Abrolhos (ABB). No contato entre os dois, ocorre um canal estreito com direção de $\mathrm{N} 65^{\circ} \mathrm{E}$, comprimento de $60 \mathrm{~km}$, largura de $15 \mathrm{~km}$ e profundidade de 1700m, chamado de Passagem de Besnard (BSP, Besnard Passage; Figura 15A). Segundo o IHO, a profundidade máxima é $1900 \mathrm{~m}$. A morfologia submarina sugere que este banco fazia parte contínua da plataforma continental e foi submetida ao afinamento da crosta continental e consequente desintegração. Este canal corresponde ao processo inicial de rifte continental. Desta forma, considera-se que o Banco Besnard (BSB) não é um edifício vulcânico, mas uma plataforma continental fragmentada e desintegrada.

O Monte Submarino de Vitória e o Banco de Congress, em conjunto, apresentam uma forma alongada com inflexão no meio (Figura 15B). Entre Monte Submarino de Vitória e Banco de Besnard, ocorre uma área de extensão de $80 \mathrm{~km}$ x $80 \mathrm{~km}$ com profundidade aproximada de $2000 \mathrm{~m}$. O fundo do oceano tem poucos relevos indicando cobertura de depósitos sedimentares. Esta área apresenta morfologia de platô com altura de $1500 \mathrm{~m}$ relativo à planície abissal (Figura
15), denominado Platô Submarino de Besnard (BSH). No platô, ocorrem montes submarinos de forma cônica com 1000 $\mathrm{m}$ a $2000 \mathrm{~m}$ de altura e cerca de $10 \mathrm{~km}$ de diâmetro na base (SM6 SM10, Figura 15). Essas saliências circulares podem ser pequenos edifícios vulcânicos.

O talude norte do Monte Submarino Vitória e do Banco de Congress é sub-paralelo ao talude sul do Banco Besnard, apresentando um bom encaixe (Figura 16). Portanto, o Monte Submarino de Vitória e Banco de Congress poderiam ter constituído parte da plataforma continental Abrolhos (ABB) e esses foram desintegrados e transportados até a presente posição com uma distância de migração de $150 \mathrm{~km}$ na época do estágio inicial da separação dos continentes. Neste sentido, considera-se que esses também não são edifícios vulcânicos, mas fragmentos de plataforma continental desintegrados. Esses três bancos (BSB, VTR, CGB), junto com a Plataforma Continental de Abrolhos (ABB), mesmo que sejam constituídos principalmente por rochas félsicas de crosta continental, podem estar sob forte influência do magmatismo básico e ultrabásico, tal como intrusões de diques e sills.

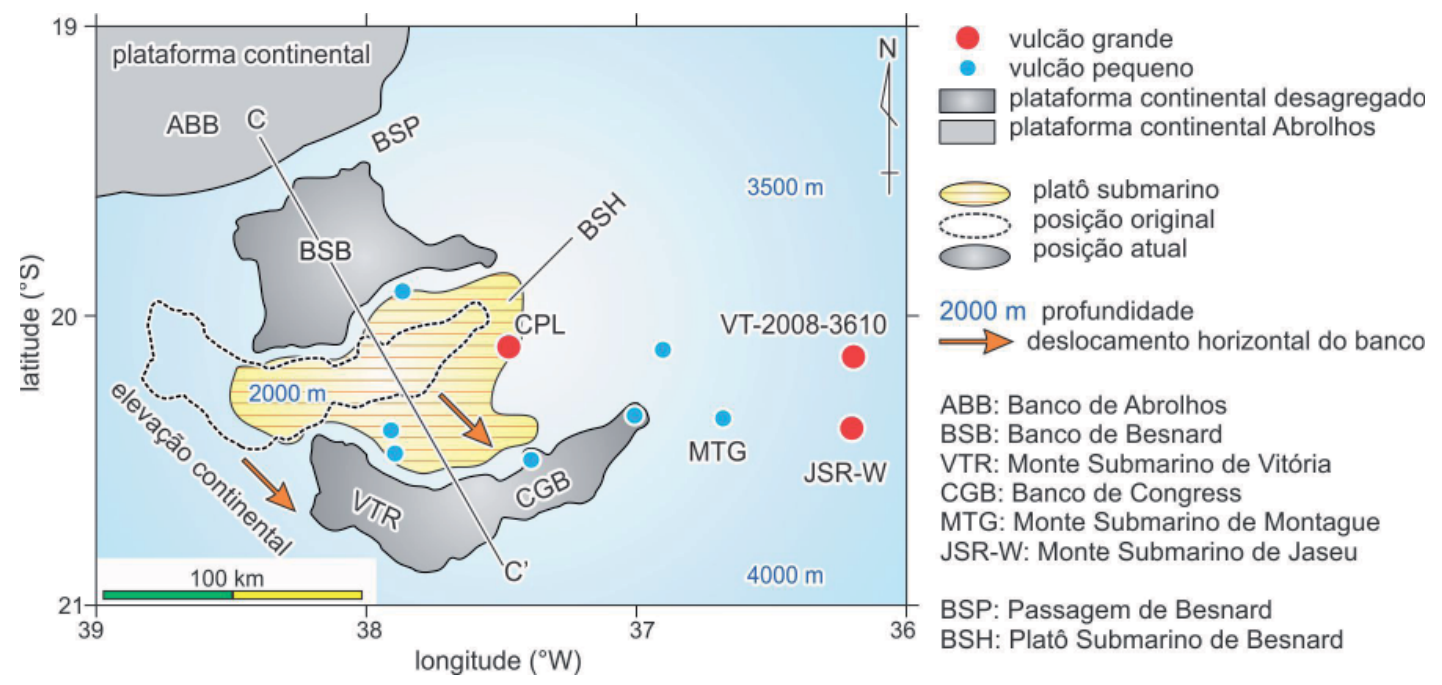

Figura 16 - Modelo proposto de plataforma continental desintegrado do Banco de Besnard (BSB), Monte Submarino de Vitória (VTR) e Banco de Congress (CGB), apresentando também as feições peculiares do Platô Submarino de Besnard (BSH) e Passagem de Besnard (BSP).

O Banco de Besnard tem fortes indícios geomorfológicos de ser plataforma continental desagregada, porém aqueles para o Monte Submarino de Vitória e o Banco de Congress não possuem evidencias tão fortes. Rangel (1998) apresentou a modelagem para a estrutura crustal sob o Monte Submarino de Vitória com base no reajuste entre o sinal gravimétrico calculado e observado. Segundo este modelo, o Monte Submarino de Vitória é constituído por três edifícios vulcânicos e depósitos sedimentares (Figura 17). Entretanto, o fundo do oceano estimado pela referida modelagem não apresenta o topo planar de $50 \mathrm{~m}$ de profundidade com 1420 $\mathrm{km}^{2}$ de expansão. Em adição, o sedimento entre os vulcões, que foi depositado após as erupções (Figura 17, setas), não pode constituir a superfície do topo planar. A modelagem da estrutura da crosta com base somente nos dados gravimétricos não combina com os dados batimétricos medidos. Este fato sugere que é necessária uma nova interpretação geofísica com a integração dos dados geomorfológicos. 


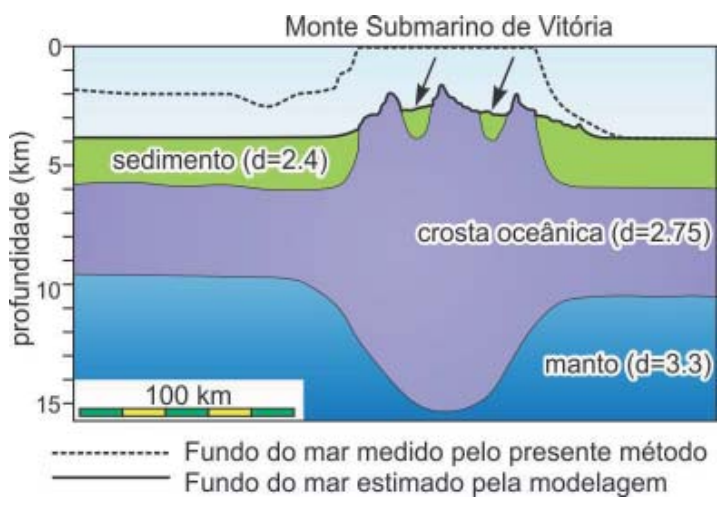

Figura 17 - Comparação entre o perfil batimétrica do Monte Submarino de Vitória pelo presente método (curva tracejada) e a estrutura crustal com base na modelagem geofisica pelo ajuste entre o sinal gravimétrico calculado e observado (Rangel, 1998; curvas contínuas).
Conforme a Figura 5B e 5D, o mapa batimétrico com base no TOPO ver. 14.1, em certos casos, possui uma boa correlação com as estruturas geológicas subjacentes. Utilizando esta característica, os autores propõem um perfil geológico hipotético para esta área. Acredita-se que o contato entre a crosta e manto é muito mais complexo do que a figura, com presença de numerosas falhas. O perfil mostra didaticamente processo de separação do continente e abertura do oceano: 1) Formação do rifte continental (BSP); 2) Abertura inicial e formação de bacia sedimentar da margem continental (BSH); 3) Expansão do oceano com crosta basáltica da Bacia Oceânica de Trindade (TOB). Conforme a idéia da Figura 18, a separação e afastamento entre Banco de Besnard e Monte Submarino Vitória formou o platô submarino de Besnard.

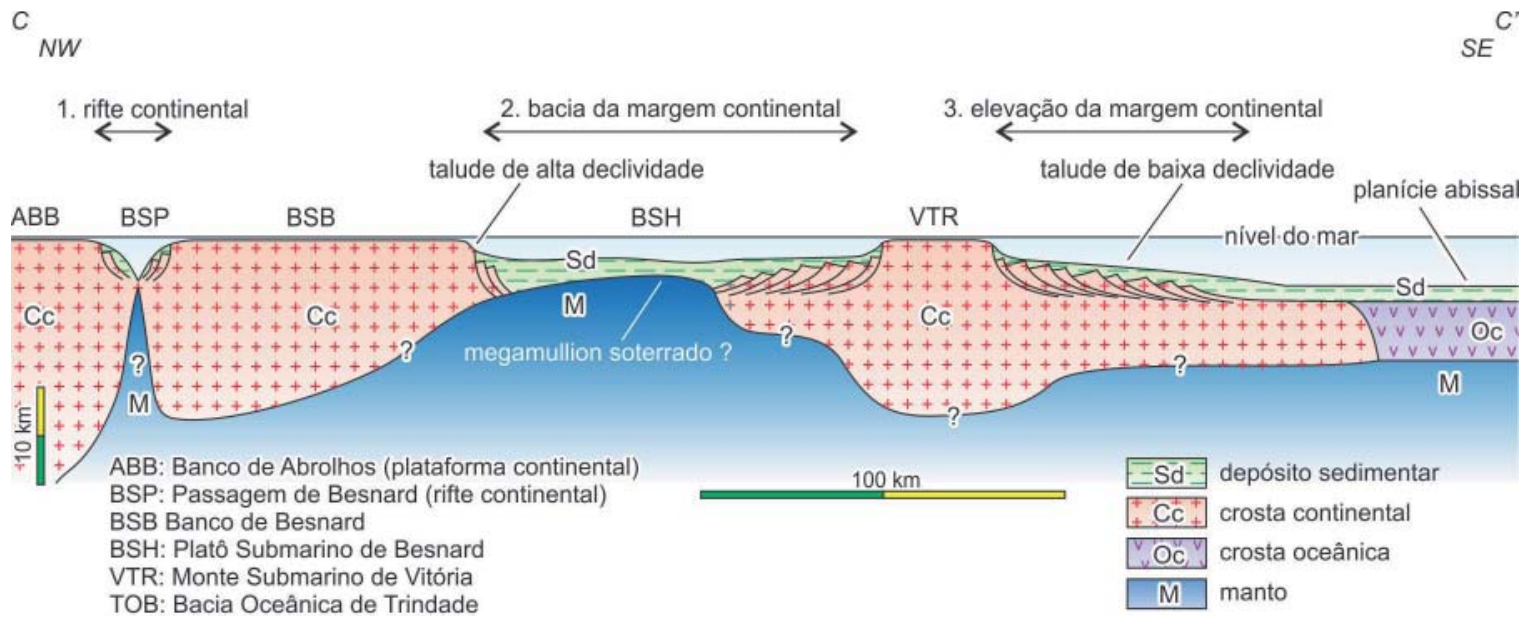

Figura 18 - Perfil geológico esquemático estimado a partir da morfologia do fundo do oceano (Figura 15) para a plataforma continental do Banco de Abrolhos (ABB), Rifte Continental da Passagem de Besnard (BSP), Banco de Besnard (BSB), Platô Submarino de Besnard (BSH) e planície abissal (ABP). As escalas são aproximadas. Refere-se a Figura 1 e Figura 16 para a posição aproximada da linha do perfil C-C'.

A separação continental e a abertura do oceano iniciamse a partir do rifte continental. Quando a expansão das placas é rápida ocorre geração do magma basáltico e consequente formação da crosta oceânica. Quando a expansão é muito lenta, não ocorre geração do magma e formação da crosta oceânica e ocorre a exposição do manto no fundo do oceano, o fenômeno denominado exumação do manto (Burn \& Beslier, 1996; Whitmarsh et al., 2001; Ritzwoller et al., 2003). Neste caso, ocorre falha sub-horizontal no contato das placas, denominado falha de descolamento (detachment fault). O bloco superior da falha é constituído por crosta oceânica de composição basáltica e o bloco inferior por manto de composição ultramáfica (Canales et al., 2004). O manto exumado forma frequentemente a saliência morfológica de
1000 a 2000m de altura relativa, denominado megamullion (Cann et al., 1997; Blackman et al., 1998; Tucholke et al, 1998; 2001; Ohara et al., 2001). Caso haja a exumação do manto no Platô Submarino de Besnard, a profundidade rasa do platô submarino em comparação com a planície abissal pode ser atribuída ao efeito de megamullion.

A ideia apresentada na Figura 18 ainda é uma hipótese de trabalho. A área de exumação do manto pode ser muito menor. Caso haja, ocorreriam a serpentinização das rochas ultramáficas do manto, hidrotermalismo de baixa temperatura e consequente geração de $\mathrm{CH}_{4}$ e $\mathrm{H}_{2}$ de origem abiogenética (e.g. Horita \& Berndt, 1999; Holm \& Chrlou, 2001; Colon et al., 2002; Charlou et al., 2002; Fruh-Green et al., 2003; Proskurowski, 2008), sendo importante sob ponto de vista de 
recursos energéticos de hidrocarbonetos. Para a conclusão, são desejados dados detalhados de magnetometria, gravimetria e prospecção sísmica, além de batimetria detalhada por multi-feixe.

\section{Conclusão}

O mapa topográfico do fundo do oceano com base nos dados de batimetria predita do banco TOPO (UCSDSIO, 2011, ver. 14.1) apresentou uma notável elevação na resolução geográfica das morfologias submarinas (Figura 2), desenvolvendo estudos geomorfológicos da Cadeia VitóriaTrindade e das áreas adjacentes, apresentando as seguintes conclusões.

A Cadeia Vitória-Trindade é constituída aproximadamente por 30 montes submarinos vulcânicos. Esses apresentam posicionamento espacial altamente linear com a inflexão na parte central. $\mathrm{O}$ trecho oriental tem direção de $\mathrm{N} 85^{\circ} \mathrm{E}$ e o trecho ocidental, de $\mathrm{N} 77^{\circ} \mathrm{W}$.

Muitos montes submarinos são compostos de elevação no sopé, edifício vulcânico principal e topo planar. A elevação no sopé tem altura típica de $1000 \mathrm{~m}$ e o edifício vulcânico tem altura representativa de $3000 \mathrm{~m}$. De oeste para leste, os vulcões tornam-se menos frequentes, a elevação no sopé, menos expressiva e as atividades magmáticas e tectônicas se tornam menos intensas.

Os vulcões Martim Vaz, Trindade do Norte e Trindade do Sul são os mais jovens e não apresentam deslizamentos no talude dos vulcões. A morfologia do deslizamento torna-se mais frequente e mais expressiva de leste para oeste da Cadeia, sugerindo que os vulcões tornam-se mais antigos de leste para oeste. $\mathrm{O}$ topo planar dos montes submarinos tem profundidade aproximada de $50 \mathrm{~m}$. Não se observa a subsidência do assoalho oceânico ao longo da Cadeia Vitória-Trindade.

O Banco de Besnard, Monte Submarino de Vitória e Banco de Congress são caracterizados pela forma não cônica, topo planar extenso, e ângulo bi-modal do talude, sendo muito diferentes dos demais montes submarinos vulcânicos. Estes bancos são considerados como fragmentos desintegrados de plataforma continental.

\section{Agradecimento}

A execução do presente trabalho foi possível graças ao equipamento da informática de alto desempenho como o computador de especificação especial montado por encomenda. Os autores agradecem à FAPERJ (Fundação de Amparo de Carlos Chagas Filho, do Estado do Rio de Janeiro) pelo apoio financeiro. Os autores são gratos à Dras. Susanna Eleonora Sichel, Eliane da Costa Alves e Isa Brheme da Universidade Federal Fluminense aos importantes debates científicos.

\section{Referências Bibliográficas}

ALMEIDA, F.F.M. As ilhas oceânicas brasileiras e uma hipótese sobre a origem do Atlântico. Anais da Academia Brasileira de Ciências, Rio de Janeiro, v. 37 supplementary volume, p. 141-145, 1965.

ALMEIDA, F.F.M. Geologia e Petrologia da Ilha da Trindade. DGM/DNPM (National Department of Mineral Production, Brazilian Federal Government), Monography XVIII, 197 p. 1961.

ALVES, E.C.; MAIA, M.; SICHEL, S.E.; CAMPOS, C.M.P. Zona de fratura de Vitória-Trindade do Oceano Atlântico Sudeste e suas implicações tectônicos. Revista Brasileira de Geofísica, v. 24, n. 1, p. 117-127, 2006.

BLACKMAN, D.K.; CANN, D.J.R.; JANSSEN, B.; SMITH, D.K. Origin of extensional core complexes evidence from the Mid-Atlantic Ridge at Atlantis Fracture Zone. Journal of Geophysical Research, v, 103, p. 21315-21333, 1998.

BURN, J.P. \& BESLIER, M.O. Mantle exhumation at passive margins. Earth and Planetary Science Letters, v. 142, 161-173, 1996.

CAINELLI, C., MOHRIAK, W.U. Geology of Atlantic Eastern Brazilian basins. 1998. In: AAPG, International Conference \& Exhibition, Short Course - Brazilian Geology Part II, Rio de Janeiro, Brazil, 67 p.

CANALES, J.P.; TUCHOLKE, B.E.; COLlins, J.A. Seismic reflection imaging of an oceanic detachment fault: Atlantis megamullion (Mid-Atlantic Ridge, $\left.30^{\circ} 10^{\prime} \mathrm{N}\right)$. Earth and Planetary Science Letters, v. 232, p. 543-560, 2004.

CANN, J.R.; BLACKMAN, D.K.; SMITH, D.K.; MCALLISTER, E.; JANSSEN, B.; MELLO, S.; AVGERIONS, E.; PASCOE, A.R.; ESCARIN, J. Corrugated slip surfaces formed at ridge transform interactions on the Mid-Atlantic Ridge. Nature, v. 385, p. 329-332, 1997.

CHARLOU, J.L.; DONVAL, J.P.; FOUQUET, Y.; JEANBAPTISTE, P.; HOLM, N. Geochemistry of high $\mathrm{H}_{2}$ and $\mathrm{CH}_{4}$ vent fluids issuing from ultramafic rocks at the Rainbow hydrothermal field $\left(36^{\circ} 14^{\prime} \mathrm{N}, \mathrm{MAR}\right)$. Chemical Geology, v. 191, n. 4 , p. $345-359,2002$.

CHERKIS, N.Z.; CHAYES, D.A.; COSTA, L.C. The bathymetry and distribution of the Bahia Seamounts, Brazil Basin. Marine Geology, v. 103, n. 1-3, p. 335-347, 1992.

COLON, C.F.J.; DONVAL, J.P.; FOUQUET, Y.; PRIEUR, D.; APPRIOU, P. The rainbow vent fluids $\left(36^{\circ} 14^{\prime} \mathrm{N}, \mathrm{MAR}\right)$ : the influence of ultramafic rocks and phase separation on trace metal content in Mid-Atlantic Ridge hydrothermal fluids. Chemical Geology, v. 184, n. 1-2, p. 37-48, 2002 . 
CORDANI U.G. Idade do vulcanismo no Oceano Atlântico Sul. Boletim de Instituto de Geociências e Astronomia, USP. São Paulo, v. 1, p. 9-75, 1970.

FERRARI, A.L., RICCOMINI, C. Campo de esforços plio-pleistocênico na Ilha de Trindade (Oceano Atlântico Sul, Brasil) e sua relação com a tectônica regional. Revista Brasileira de Geologia, São Paulo, v. 29, n. 2, 195-202, 1999.

FODOR, R.V. \& HANAN, B.B. Geochemical evidence for the Trindade hotspot trace: Columbia seamount ankaramite. Lithos, v. 51, p. 293-304, 2000.

FRUH-GREEN, G.L.; KELLEY, D.S.; BERNASCONI, S.M.; KARSON, J.A.; LUDWIG, K.A.; BUTTERFIELD, D.A.; BOSCHI, C.; PROSKUROWSKI, G. 30,000 Years of Hydrothermal Activity at the Lost City Vent Field. 30,000 Years of Hydrothermal Activity at the Lost City Vent Field. Science, v. 301, p. 495-498, 2003.

GLADCZENKO, T.P.; HINZ, K.; ELDHOLM, O.; MEYER, H.; NEBEN, S.; SKOGSEID, J. South Atlantic volcanic margins. Journal of the Geological Society, London, v. 154, p. 465-470, 1997.

GOMES, P.O.; GOMES, B.S.; PALMA, J.J.C.; JINNO, K.; SOUZA, J.M. Ocean-continent transition and tectonic framework of the oceanic crust at the continental margin off NE Brazil: results of LEPLAC Project. In: MOHRIAK, W.U., TALWANI, M. Eds. Atlantic rifts and continental margins, AGU Geophysical Monograph, v. 115, p. 261291, 2000.

HERZ, N. Timing of spreading in the South Atlantic: Information from Brasilian alkalic rocks. Geological Society of America Bulletin, v. 88, p. 101-112, 1977.

HOLM, N.G. \& CHARLOU, J.L. Initial indications of abiotic formation of hydrocarbons in the Rainbow ultramafic hydrothermal system, Mid-Atlantic Ridge. Earth and Planetary Science Letters, v. 191, n. 1-2, p. 1-8, 2001.

HORITA, J. \& BERNDT, M.E. Abiogenic Methane Formation and Isotopic Fractionation Under Hydrothermal Conditions. Science, v. 285, p. 1055-1057, 1999.

LIMA, A.F.; FAUGERES, J.C.; MAHIQUES, M. The Oligocene-Neogene deep-sea Columbia Channel system in the South Brazilian Basin: Seismic stratigraphy and environmental changes. Marine Geology, v. 266, p. 18-41, 2009.

MARQUES, L.S.; ULBRICH, M.N.C.; RUBERTI E.; TASSINARI, C.G. Petrology, geochemistry and Sr-Nd isotopes of Trindade and Martim Vaz volcanic rocks (Southern Atlantic Ocean). Journal of Volcanology and Geothermal Reserach, v. 93, p. 191-216, 1999.
MASSÉ, L.; FAUGÈRES, J.C. ; HROVATIN, V. The interplay between turbidity and contour current processes on the Columbia Channel fan drift, Southern Brazil Basin. Sedimentary Geology, v. 115, p. 111-132, 1998.

MCNUTT, M.K. Lithospheric flexure and thermal anomalies. Journal of Geophysical Research, v. 89, n. B13, p. 1118011194, 1984.

MOHRIAK, W.U. Bacias Sedimentares da Margem Continental Brasileira. In BIZZI, L.A., SCHOBBENHAUS, C., VIDOTTI, R.M., GONÇALVES, J.H. Eds. Geologia, Tectônica e Recursos Minerais do Brasil. CPRM, Brasília, p. $87-165,2003$.

MOHRIAK W.U. Interpretação geológica e geofísica da Bacia do Espírito Santo e da região de Abrolhos: petrografia, datações radiométricas e visualização sísmica das rochas vulcânicas. Boletim de Geociências da Petrobras, v. 14, p.133-142, 2005.

MOHRIAK, W.U., NEMČOK, M., ENSCISO, G. South Atlantic divergent margin evolution: rift-border uplift and salt tectonics in the basins of SE Brazil. Geological Society, London, Special Publications, v. 294, p. 365 398, 2008.

MOHRIAK, W.U., NÓBREGA, M., ODEGARD, M.E., GOMES1, B.S., DICKSON, W.G. Geological and geophysical interpretation of the Rio Grande Rise, southeastern Brazilian margin: extensional tectonics and rifting of continental and oceanic crusts. Petroleum Geoscience, v. 16, p; 231-245, 2010.

MORGAN, W. J. Convection plumes in the lower mantle. Nature, v. 230, 42-43, 1971.

MORGAN, W.J. Plate motions and deep mantle convections. Geological Society of America Memorium, v. 152, p. 7-22. 1972.

MORGAN, W.J. Deep mantle convection plumes and plate motions, American Association of Petroleum Geology Bulletin, v. 56, p. 203-213, 1978.

MOTOKI, A.; ZUCCO, L.L.; SICHEL, S.E.; AIRES, J.R.; PETRAKIS, G.H. Desenvolvimento da técnica para especificação digital de cores e a nova nomenclatura para classificação de rochas ornamentais com base nas cores medidas. Geociências, Rio Claro, v. 25, n. 4, p. 403-415, 2006.

MOTOKI, A.; PETRAKIS, G.H.; SOARES, R.S.; SICHEL, S.E.; AIRES, J.R. New method of semiautomatic modal analyses for phenocrysts of porphyritic rocks based on quantitative digital colour specification technique. Revista Escola de Minas, Ouro Preto, v. 60, n. 1, p. 13-20. 2007. (a) 
MOTOKI, A.; NOVAIS, L.C.C.; SICHEL, S.E.; NEVES, J.L.; AIRES, J.R. Felsic pyroclastic rock originated from subaqueous eruption in the Espírito Santo sedimentary basin: an association with the tectonic-sedimentary model. Geociências, Rio Claro, v. 26, n. 2, 151-160, 2007. (b)

MOTOKI, A.; PETRAKIS, G.H.; SICHEL, S.E.; CARDOSO, C.E.; MELO, R.C.; SOARES, R.S.; MOTOKI, K.F. Landform origin of the Mendanha Massif, State of Rio de Janeiro, Brazil, based on the geomorphological analyses by summit level map technique. Geociências, Rio Claro, v. 27, n. 1, p. 99-115, 2008.

MOTOKI, A.; SICHEL, S.E.; CAMPOS, T.F.C.; SRIVASTAVA, N.K.; SOARES, R.S. Present-day uplift rate of the Saint Peter and Saint Paul Islets, Equatorial Atlantic Ocean. REM-Revista Escola de Minas, Ouro Preto, v. 62, n. 3, p. 331-342, 2009.

MOTOKI, A., MOTOKI, K.F. Origem dos relevos do maciço Mendanha, RJ, movimento de falhas ou erosão diferencial ?: análises geomorfológicas por seppômen e sekkokumen com base do ASTER GDEM. Anais do $\mathbf{1 3}^{\circ}$ Simpósio Nacional de Estudos Tectônicos, Campinas, SBG, CD, 378-38, 2011.

NOVAIS, L.C.C.; TEIXEIRA, L.B.; NEVES, M.T.; RODARTE, J.B.M.; ALMEIDA, J.C.H.; VALERIANO, C.M. Novas ocorrências de diques de diabásio na faixa Colatina - ES: estruturas rúpteis associadas e implicações tectônicas para as bacias de Campos e do Espírito Santo. Boletim de Geociências da Petrobrás, Rio de Janeiro, v. 12, n. 1, p. 191-194. 2003.

O'CONNOR, J.M. \& ROEX, A.P. South Atlantic hot spotplume systems: 1. Distribution of volcanism in time and space. Earth and Planetary Science Letters, v. 113, p. 343-364, 1992.

OHARA, Y.; YOSHIDA, T.; KATO, Y.; KASUGA, S. Giant megamullion in the Parece Vela backarc basin. Marine Geophysical Research, v. 22, p. 47-61. 2001.

OREIRO, S.T.; CUPERTINO, J.A.; SZATMARI, P.; THOMÁZ-FILHO, A. Influence of pre-salt alignments in post-Aptian magmatism in the Cabo Frio High and its surroundings, Santos and Campos basins, SE Brazil: An example of non-plume-related magmatism. Journal of South American Earth Sciences, v. 25, p. 116-131, 2008 .

PALMA, J.J.C. Fisiografia da área oceânica. In: Schobbenhaus, C., Campos, d.A., Derze, G.R., Asmus, H.E. Eds. Geologia do Brasil. Texto explicativo do mapa geológico do Brasil e da área oceânica adjacente incluindo depósitos minerais. Escala 1:2.500.500. Capítulo XI. Departamento Nacional de Produção Mineral (DNPM), Rio de Janeiro.
PROSKUROWSKI, G.; LILLEY, M.D.; SEEWALD, J.S.; FRUH-GREEN, G.L.; OLSON, E.J.; LUPTON, J.E.; SYLVA, S.P.; KELLEY, D.S. Abiogenic Hydrocarbon Production at Lost City Hydrothermal Field. Science, 319-1, 5863, 604-607, 2008.

QUILTY, P.G. Late Eocene foraminifers and palaeoenvironment, Cascade Seamount, southwest Pacific Ocean: implications for seamount subsidence and AustraliaAntarctica Eocene correlation. Australian Journal of Earth Sciences, v. 48, n. 5, p. 633-641, 2001.

RANGEL A.A. Aplicação de métodos geofísicos para a determinação da estrutura crustal da Cadeia VitóriaTrindade. Niterói, 1998, 97p. Dissertação (Mestrado em Geofísica) - Departamento de Geologia da Universidade Federal Fluminense. (inédito)

RITZWOLLER, M.H.; SHAPIRO, N.M.; LEAHY, G.M. A resolved mantle anomaly as the cause of the AustralianAntarctic discordance, Journal of Geophysical Research, v. 108-B12, p. 2559, 2003.

SICHEL, S.E.; ESPERANÇA, S.; MOTOKI, A.; MAIA, M.; HORAN, M.F.; SZATMARI, P.; ALVES, E.C.; MELLO, S.L.M. Geophysical and geochemical evidence for cold upper mantle beneath the Equatorial Atlantic Ocean. Revista Brasileira de Geofísica, v, 26, n. 1, p. 69-86, 2008.

SKOLOTNEV, S.G.; PEYVE, A.; TRUKO, N.N. New data on the structure of the Vitoria-Trindade seamount chain (western Brazil basin, South Atlantic). Doklady Earth Sciences, v. 431, n. 2, p. 435-440, 2010.

SKOLOTNEV, S.G., BYLINSKAYA, M.EE., GOLOVINA, L.A, IPAT'EVA, I.S. First Data on the Age of Rocks from the Central Part of the Vitoria-Trindade Ridge (Brazil Basin, South Atlantic). Doklady Earth Sciences, v. 437, n. 1, p. 316-322, 2011.

SMITH, W.H. \& SANDWELL, D.T. Global sea floor topography from satellite altimetry and ship depth soundings. Science Magazine, v. 277, n, 5334, p. 19571962, 1997.

SOUZA, K.G. La Marge Continentale Bre`silienne Sud Orientale et les Domaines Oceaniques Adjacents: Structure et Evolution. Villefranche Sur Mer, 1991, 230p Tèsee (Doctorat) - Universite' Pierre et Marie Curie. (inédito)

STEINBERGER, B. Plumes in a convecting mantle: Models and observations for individual hotspots, Journal of Geophysical Research, v. 105, p; 11127-11152, 2000.

THOMÁZ-FILHO, A. \& RODRIGUES, A.L. O alinhamento de rochas alcalinas Poços de Caldas-Cabo Frio (RJ) e sua 
continuidade na Cadeia Vitória-Trindade. Revista Brasileira de Geociências. v. 29, n. 2, p. 189-194, 1999.

TUCHOLKE, B.E.; LIN, J.; KLEINROCK, M.C. Megamullions and mullion structure defining oceanic metamorphic core complex on the Mid-Atlantic Ridge. Journal of Geophysical Research, v. 103, p. 9857-9866, 1998.

TUCHOLKE, B.E.; FUJIOKA, K.; ISHIHARA, T.; HIRTH, G.; KINOSHITA, M. Submersible study of an oceanic megamullion in the central North Atlantic. Journal of Geophysical Research, v. 106, p. 16145-16161, 2001.

UCSD-SIO. Measured and estimated seafloor topography. Scripps Institution of Oceanography, University of California, San Diago. http://topex.ucsd.edu/marine_topo/ mar_topo.html. Acesso em 14 de julho de 2011.

ULBRICH M.N.C. Petrography of alkaline volcanicsubvolcanic rocks from the brazilian Fernando de Noronha archipelago, Southern Atlantic Ocean. Boletim do Instituto de Geociências da Universidade de São Paulo, Série Científica, São Paulo, v. 24, p. 77-94, 1994.

VALENCIO D.A. \& MENDÍA J.E. Paleomagnetism and $\mathrm{K}-\mathrm{Ar}$ age of some rocks of the Trindade Complex and the Valado Formation from Trindade Island, Brazil. Revista Brasileira de Geociências. São Paulo, v. 4, p. 124-132, 1964.

WHITMARSH, R.B.; MANATSCHAL, G.; MINSHULL, T.A. Evolution of magma-poor continental margins from rifting to seafloor spreading. Nature, v. 143, p. 150-154, 2001 .

ZALÁN, P.V.; SEVERINO, M.C.G.; RIGOTI, C.A.; MAGNAVITA, L.P.; BACH, J.A. An Entirely New 3DView of the Crustal and Mantle Structure of a South Atlantic Passive Margin - Santos, Campos and Espírito Santo Basins, Brazil. Americal Association of Petroleum Geology, Annual Convention and Exhibition, Houston, $12 \mathrm{p}, 2011$. 